\title{
From Columbia Studio B to Carnegie Hall: The Studio-to-Stage Creative Trajectory in the Fusion Jazz of Miles Davis
}

\author{
Timothy Douglas Booth
}

A thesis submitted to Massey University and Victoria University of Wellington

in partial fulfilment of the requirements for the degree of Master of Music in Musicology

New Zealand School of Music 
(C) Copyright by

Timothy Douglas Booth All rights reserved

September 2015 


\begin{abstract}
This thesis proposes an interrelationship between the creative processes of the recording studio and the concert stage in the fusion jazz of Miles Davis. Recent scholarship highlights the importance of the recording studio to fusion jazz musicians as they developed unique approaches to composition and improvisation. While providing valuable insight into the studio-derived creative processes distinctive of fusion jazz, this scholarship inadvertently obscures some of the live performance practices of fusion jazz musicians. Turning attention towards live performance, yet without neglecting the insights of this recent scholarship, I consider how the creative processes forged by Davis in the recording studio manifested in his activities as a concert artist. Combining commentary on Davis's formative fusion jazz studio recordings (produced between 1969 and 1972) with analyses of the live album Dark Magus (exemplary of his mid-1970s concert performances), this thesis suggests a reorientation in Davis's conceptions of improvisation and composition during this period by highlight some of the creative processes he engaged in, both in the recording studio and on the concert stage.

Drawing on the accounts of several musicians who worked with Davis in the recording studio during the late-1960s and early 1970s, I consider how postproduction tape editing allowed Davis and his band a new means for composing and improvising in the studio. Then, to demonstrate what I have termed a studio-to-stage creative trajectory, I analyse two creative processes common to Davis's mid-1970s concerts as evidenced in Dark Magus: Davis's on-stage direction of sudden, rhythm section cuts in the midst of lead instrumentalists' improvisations; and the featured use of two accompanimental instruments unusual to jazz performance-a YC45 electric organ (played by Davis himself) and a drum machine (played by percussionist James Mtume). Finally, framing this studio-to-stage creative trajectory in terms of performance theorist Philip Auslander's concept of liveness, I claim that Davis's fusion jazz stands as an example of mediatization rich in agency. I then suggest that the work of other fusion jazz musicians and musicians associated with other jazz styles could be usefully reappraised using a similar methodology that explores the role of record production in creative process.
\end{abstract}





\section{Acknowledgements}

Very special thanks are owed to the following people:

- My supervisors: Elizabeth Hudson and David Cosper

- My colleagues: Ailsa Lipscombe and David Laidler

- My family: Kevin, Chris, Jessica and Connie Booth, and Irene Back

- My partner: Michelle Peterson

The completion of this thesis would have been impossible without the support you have each shown me.

Thank you. 



\section{Table of Contents}

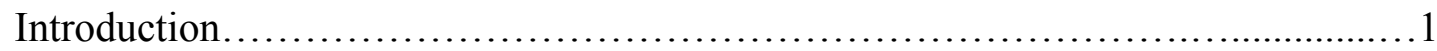

Chapter One: Fusion Jazz in the Studio and on the Stage........................... 9

Chapter Two: The Creative Process in Davis's Fusion Jazz Studio Albums.......23

Chapter Three: The Rhythm Section Cut.....................................36

Chapter Four: Disorientating Sound as Interactive Accompaniment...............53

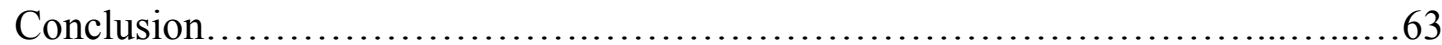

Appendix..............................................................68

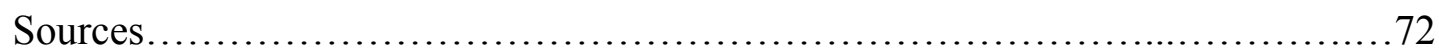





\section{List of Figures}

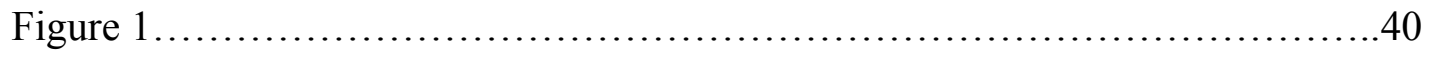

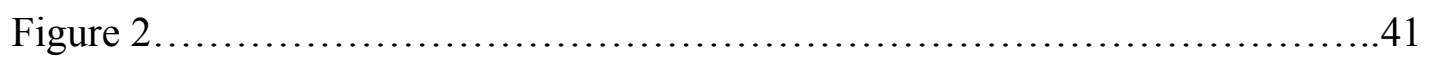

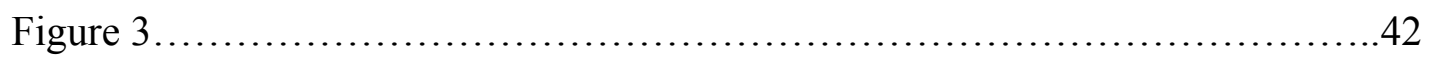




\section{Introduction}

The fusion jazz of the late-1960s and 1970s has been traditionally defined as a style that combines the musical materials and instruments of jazz and rock. Frequently coupled with this definition is an assumption that this stylistic development in jazz was motivated first and foremost by economic factors. Esteemed jazz critic Leonard Feather expressed this view potently when he wrote:

If the year 1970 is remembered in connection with any outstanding event in the history of jazz, musicologists may recall it as the Year of the Whores. Never before, no matter how grievous the economic woes of jazz musicians...at any prior point in jazz time, did so many do so little in an attempt to earn so much. ${ }^{1}$

Through into the 1980s and much of the 1990s, Feather's total dismissal of fusion jazz seemed to echo throughout the historiographical discourse on fusion jazz. Thus for many years, as a jazz style marginalized in music scholarship, fusion jazz was left significantly understudied. Since the 1990s, however, the historical study of fusion jazz has gained considerable momentum. This literature consists of a combination of attention to the music's material structure and examinations of the music in its social and cultural context. This work can be seen to have cleared a space within music scholarship for fusion jazz, validating and legitimizing its study in the academy.

Of this recent fusion jazz historiography, perhaps the most illuminating is the scholarship that attends to creative process. In looking not just at how the music sounds or how it was received by its audiences, but also at how the music was created, these scholars have drawn focused attention to a new key defining factor of the music, one which has been largely ignored: record production. These scholars have demonstrated that not only were fusion jazz musicians adopting the instruments and musical materials common to a range of concurrent genres, but they were also adapting some of the record production techniques common to these genres and blending these with compositional and improvisational methods of earlier jazz styles. Instead of using recordings to document improvised performances based on precomposed works - as most jazz musicians and producers had done before them-

1 Quoted in Marv Hohman and Charles Mitchell (eds.), 'Down Beat in Review: A Collection of Lunacy, Prophecy, Controversy and Commentary from 42 Years of the Contemporary Music Magazine', Down Beat (July 15 1976), 15. 
fusion jazz musicians would often engage in the composition process in the studio by recording fragments of improvised and pre-composed material and then, through a process of cutting and splicing magnetic tape, they would create the final work in post production. This new creative process, which shared its phonographic-method with rock artists such as the Beatles, the Beach Boys and Jimi Hendrix as the musique concrète compositions of Pierre Schaeffer, saw fusion jazz musicians develop new approaches to musical creation, further integrating the technology of the recording studio into the creative processes of composition and improvisation.

In foregrounding the new approaches fusion jazz musicians were taking to record production, these scholars have proffered a salient feature of the musicarguably one of its most definitive features - with which to compare it to earlier and concurrent jazz styles, thus significantly advancing the depth and scope of jazz historiography. Yet if we are to accept fusion jazz as a distinctly phonographic style of music - a music which is not simply represented by, but created with, recording technology — what is to be made of the music created by fusion jazz musicians in live performance settings? As the plethora of live fusion jazz recordings plainly demonstrate and the accounts of musicians and audiences avidly attest, the role of live performance in fusion jazz was an important facet of the music's production and reception. What is more, given the continued prevalence of improvisation in fusion jazz, the live performance setting provided musicians and audiences a vital creative space to engage in the music; fusion jazz was no less a performance art as the jazz styles that had come before it. Jazz historians are thus left with a significant problem when it comes to understanding the broader creative processes of fusion jazz musicians: if, on the one hand, the recording process was an essential stylistic element of fusion jazz, while on the other hand, live performance was still a fundamental site for its production and reception, how can this apparent contradiction be reconciled? If the recording process was so fundamental to fusion jazz musician's creative processes, is it possible that it would have affected their total output - including their concert performances - not just their studio-produced recordings? Is it possible, then, that there exists in fusion jazz an interrelationship between the creative processes of the recording studio and the concert stage? The following thesis is an attempt to address this question.

As a starting point for exploring the potential of a studio-stage interrelationship in fusion jazz, I have decided to focus my attention on the work of a 
single fusion jazz musician: the style's most prominent figure, Miles Davis. Widely recognized as having popularized fusion jazz, Davis has been both extolled and berated for propagating the style, bringing it into the spotlight of the jazz world andgiven his high profile-legitimizing the new stylistic development. Fusion jazz was, in historian Ted Gioia's words, "Davis's legacy.," Not only did Davis produce some of the most critically acclaimed and commercially successful fusion jazz recordings (his 1970 release of Bitches Brew sits in numerous "best of" album lists while also being Davis's first gold-selling record), he also mentored several of fusion jazz's most prominent figures. The Mahavishnu Orchestra, Weather Report, the Head Hunters and Return to Forever, four of the most prolific fusion jazz groups, were all led by musicians who had at one time recorded or performed live with Davis during the late1960 s and 1970 s.

While it has become convenient for jazz historians to talk about the music Davis produced between 1969 and 1975 in relation to the single stylistic label of fusion jazz, doing so may obscure the sheer diversity of this music. Indeed, in comparing Davis's formative fusion jazz recordings released during 1969 with his final commercial releases from 1975 one might struggle to discern any apparent similarities. Indeed, during this six year period Davis's music had evolved so significantly that by the mid-1970s any connection to a mainstream of jazz would seem virtually impossible to discern. What is more, in comparing his studio albums with recordings of his live performances one would struggle to find any immediate similarities give that the repertoire and instrumentation contrasted considerably.

This diversity may seem to indicate that Davis's fusion jazz does not offer an appropriate example for exploring the potential for studio-stage interrelationship in fusion jazz. Yet after having listened more carefully and widely to the available recordings of Davis's music from the late-1960s and 1970s, I came to the conclusion that there was in fact ample evidence with which to articulate a studio-stage interrelationship. This interrelationship was, however, not most evident when listening to contemporaneous studio and live recordings (say for instance Jack Johnson and Miles Davis at Fillmore, both recorded in 1970), but when comparing Davis's studio albums of the late-1960s and early-1970s with the later recordings of his concert performances from the mid-1970s. In comparing this work, it became

2 Ted Gioia, The History of Jazz (New York: Oxford University Press, 1997). 
apparent to me that two practices in particular were suggestive of a viable interrelationship between the studio and the stage. These are (1) Davis's direction of sudden and unexpected moments of silence by the rhythm section leaving the lead soloist to continue playing unaccompanied; and (2) the use of electric instruments uncommon to a jazz ensemble as featured accompaniment in support of lead soloists. These two live performance practices are heard throughout recordings of Davis's concerts between 1973 and 1975.

In this thesis I focus analytical attention on these two aspects of Davis's live performance practices by describing their use as heard in the album, Dark Magus, a live recording capturing Davis and his band in concert at Carnegie Hall in March 1974. The band heard on Dark Magus features several of the musicians who performed regularly with Davis between 1973 and 1975: saxophonist Dave Liebman; guitarist and percussionist Pete Cosey; guitarist Reggie Lucas; bassist Michael Henderson; drummer Al Foster; and percussionist James Mtume. The concert also included two guest musicians: guitarist Dominique Gaumont and saxophonist Azar Lawrence. As well as ensemble make-up, this period of 1973 to 1975 is also unified by the repertoire performed. Several of the most commonly performed pieces were "Funk-Prelude Part One", "Tune in Five", and "Ife", all of which are heard performed on Dark Magus. In this thesis I take Dark Magus as a representative sample of the band's live performances during the mid-1970s. Studio albums that I compare it two are In a Silent Way, Bitches Brew, Jack Johnson, and On the Corner, each of which was recorded between the period of 1969 and $1972 .^{3}$

On first glance, the live performance practices I address in this thesis are not likely to exhibit a clear association with the work produced by Davis in the studio. In seeking to define a studio-stage interrelationship, it may seem more obvious to compare features such as repertoire, instrumentation or the melodic material improvised by lead soloists. As noted above, however, attempts to define a studiostage interrelationship that accounts for such features are likely to be made in vein. Rather, as I aim to demonstrate in this thesis, it is more fruitful to explore the underlying creative processes from which the music emerges, than simply the musical detail itself. Following the lead not only of other fusion jazz scholars to have focused on record production, but also, more broadly, several scholars working in jazz studies,

\footnotetext{
Material for much of these albums was recorded in Studio B at Columbia Records' studios in New York City.
} 
I adopt a research methodology that foregrounds creative process. Doing so can be particularly appropriate when studying the work of jazz musicians, given the improvised and often communal nature in which the music is produced. Thus, in looking to discern an interrelationship between the fusion jazz Davis created in the recording studio and on the concert stage, I am less interested in the musical material itself, and more attracted to revealing how that music was created, and what kinds of musical conceptions allowed for its creation. Accordingly, this thesis is an attempt to articulate, what I call, a studio-to-stage creative trajectory: a theory of musical practice in which the creative processes developed and applied in the recording of Davis's studio albums go on to inform the work produced in his concert performances. Creative process, in this thesis, encompasses a wide range of practices: improvisation and composition; soloing and accompanying; and bandleadership and record production. By grouping these activities together under the banner of creative process, it is possible to think about them laterally rather than in a hierarchy and in turn easier to conceive of a studio-to-stage creative trajectory.

In this thesis I am particularly concerned with theorizing how Davis's conception of musical form could have been shaped at a fundamental level by his experiences working in the recording studio during the late-1960s and 1970s. Thinking in this way is useful if we want to situate Davis's activities as a fusion jazz musician within the upheavals in the jazz world that occurred during the two decades leading up to the emergence of fusion jazz. As has been well traversed in jazz histories, during the 1950s and 1960s, conceptions of musical structure began to change as cyclical form came to be seen less and less as an essential performance parameter in jazz. Instead of improvising material based on prescribed musical structure, jazz musicians began to improvise the formal material as well. If we are able to see Davis's musical activities in the late-1960s and 1970s — both in the recording studio and on the concert stage - in terms of how he approached the challenge of creating and negotiating musical form, then I think we can develop a more nuanced and accurate historiographic picture of fusion jazz: not only would we have a more thorough understanding of the unique ways in which the music itself was created, but we could better perceive fusion jazz within broader histories of jazz.

Before proceeding I should offer an explanation for what might seem to be some conspicuous absences in this thesis. It is important that I make clear from the outset that this thesis focuses on Miles Davis the bandleader, not Miles Davis the 
trumpet player. The role of the bandleader in jazz is unique; in fusion jazz it is no less so. What I claim the studio-to-stage creative trajectory of Davis's fusion jazz reveals first is how his time in the studio shaped his broader conceptions of bandleadership and compositional practice during the late-1960s and 1970s. It is unlikely that a thorough understanding of the melodic material of this music, and how it is created by lead soloist, can be articulated without first understanding how the formal properties of the music function. As in earlier jazz styles, the meaning we infer in an improvised melody is shaped in part by how we see a given melody as relating to its underlying harmonic and formal material. Thus, if we do not understand the formal "rules" that are in operation during Davis's fusion jazz performances, we cannot hope to gain a thorough understanding of why Davis as a trumpet player, or any of the lead soloists who perform in his group, make the musical decision they do. Thus, I am interested first in how improvisation occurs at a macro-level, across the band as a whole and in the improvised development of musical form in real-time; attention to micro-level improvisation, the activities of individual musicians, is, I feel, better understood in light of this macro-level.

I should also note here that I have intentionally avoided drawing on Davis's own words in this thesis. While Davis's commentary may be thought to provide the interpretive key to deciphering his music, to draw on his words in such a way would require a different methodology to the one I apply here. Due to the opacity of his comments on his own music I would need to focus on the complicated issues surrounding self-representation, which overshadow my attention to creative process. ${ }^{4}$ Further, I also want to avoid reinforcing notions of author intentionality as primary to understanding artistic work. ${ }^{5}$ In trying to develop an understanding of this music, while it is important to at least consider what Davis stated as his intentions - to blatantly ignore his commentary would surely be problematic - it seems to me that some of the interrelationships between the recording studio and the stage were not immediately clear at the time, even to Davis himself. Accordingly, I have sought to

4 See Ken Prouty, 'Plagiarizing Your Own Autobiography, and Other Strange Tales: Miles Davis, Jazz Discourse, and the Aesthetic of Silence', Jazz Research Journal 4/1 (2010), 15-41; and Naaman Wood, 'Uncle Tom, Massas, and Symbolic Violence: Miles Davis's Rhetoric of Moral Constitution', Jazz Perspectives 7/1 (2013), 57-75.

5 For a discussion of authorial intention in jazz see Benjamin Givan, 'Gunther Schuller and the Challenge of Sonny Rollins: Stylistic Context, Intentionality, and Jazz Analysis', Journal of the American Musicological Society 67/1 (2007), 167-237. 
draw conclusions about his actions based on the commentary of others (critics, historians and the musicians who performed with Davis) and attention to musical detail as it exists in studio albums and live concert recordings.

Finally, I want to make clear from the start that-while I see Davis's music as a salient stylistic example of fusion jazz, and at times throughout this thesis make the historical generalization of treating it as metonymic of the style, I by no means see it as the definition of fusion jazz. Indeed, it is the diversity of stylistic combinations that makes fusion jazz what it is. Additionally, there are also some significant stylistic overlaps between fusion jazz and concurrent jazz styles associated with the jazz avant garde. While I will not be discussing in any detail the music of other fusion jazz musician nor the stylistic overlaps between fusion jazz and the jazz avant garde it is nevertheless important to be aware that certain features of Davis's approach to record production and live performance during the late 1960s and 1970s both compares and contrasts with a host of other musicians working contemporaneously. And, while I am seeking to define this studio-to-stage creative trajectory as a definitive quality of Davis's fusion jazz, and at some level as a representation of fusion jazz as a style more generally, I do not intend to rule out the possibility that similar studio-stage interrelationships exist in other jazz styles. I will return at the end of this thesis to address the implications that a studio-to-stage creative trajectory in fusion jazz may have in understanding similar interrelationships in earlier jazz styles.

\section{Thesis outline}

Chapter One of this thesis provides a disciplinary point of entry into this central question of a studio-to-stage creative trajectory. I offer an overview of the work of several fusion jazz scholars, highlighting the ways in which they depart from earlier scholarly treatment of fusion jazz. I then centre upon the work of two fusion jazz scholars, Steven Pond and Jeremy Smith, and their adaption and development of new research methodologies that highlight the significance of record production in the creative processes of fusion jazz musicians. I then consider how these two scholars address the interrelationship between the work of fusion jazz musicians in the studio and on the stage.

Chapter Two offers an overview of Davis's approach to record production during the late-1960s and early-1970s. Drawing on critical commentary and 
reflections of the musicians who participated in studio sessions with Davis, I examine some of Davis's new approaches to improvisation and composition in the recording studio. I then address the reception of Teo Macero's role in the production of Davis's fusion jazz studio albums and consider how comparisons made between the producer's editing techniques and those of musique concrète composers can potentially obscure the kind of musical practices being engaged in by the musicians themselves during the creation of these albums.

Chapter Three turns to an analysis of Davis's live performance practice as the bandleader of a fusion jazz ensemble. Focusing on the live recording, Dark Magus, I address Davis's direction of rhythm section cuts heard in the Carnegie Hall performance. I argue that Davis's real-time direction of these rhythm section cuts can be understood as being informed by the bandleader's contemporaneous record production methods. Considering these cuts in terms of process rather than just product, I argue, allows us a way to view Davis's changing conception of musical form as expressed in live performance, a changing conception that was shaped by his experience of tape editing and manipulation while producing his fusion jazz studio recordings of the late 1960 s and 1970s.

Chapter Four follows the process-centred methodology of the previous chapter, addressing the featured use of unconventional electronic instruments in accompanimental roles. I focus on Davis's use of the YC45 electric organ, and percussionist James Mtume use of a drum machine. I put forward an interpretation of these accompanimental methods that consider how they are used to disorientate the lead soloists in a way that is comparable to Davis musical disorientation of his musicians during the production of his studio albums.

As a conclusion to this thesis I touch on the work of performance theorist Philip Auslander and his development of the concept of liveness. An understanding of liveness as an emergent property of mediated performance can prove highly useful in framing a conception of the interrelationship between the creative processes of Davis's studio- and stage-produced music of the late-1960s and 1970s. I then suggest that this studio-to-stage creative trajectory would give us reason to look more critically at how recordings and recording technology are implicated in the creative processes of musicians throughout jazz's history. I conclude by suggesting that to learn more about the distinctive qualities of jazz musician's creative processes we need to pay greater attention to the essential role of recordings in the music's creation. 


\section{Chapter One:}

\section{Fusion Jazz in the Studio and on the Stage}

\section{Fusion jazz historiography}

Throughout the 1970s and 1980s fusion jazz received minimal attention in jazz scholarship. What little attention it did receive all but ignored the differences in use of recording technology of fusion jazz musicians and their jazz predecessors. Being primarily concerned with the result of the musicians' activity, rather than the activity itself, this scholarship either obscured, or skirted around the fact that fusion jazz musicians were breaking with the conventions of jazz recording methods. In defining fusion jazz, two preeminent jazz scholars from this period point to the use of electric instruments as key stylistic signifiers of the music. Frank Tirro associates fusion jazz with amplification ("stakes of speakers, amplified by solid-state unites capable of vibrating the floor of an amphitheatre") as well as electric, and electrified, instruments ("electric pianos, keyboards and analog synthesizers, electric guitars and basses, microphoned standard instruments."') ${ }^{6}$ The association of high volume with electric instruments provides a contrast to earlier jazz styles and a gesture towards the burgeoning rock styles. James Lincoln Collier is explicit in drawing a connection between instruments and style, describing Davis's Bitches Brew as a "rock-orientated record sporting the full regalia of electronic devices."7

During the 1980s, as jazz's neoclassical form came to dominant the mainstream, fusion jazz was treated increasingly by jazz historians as the music's "wrong turn," and as a divergence from jazz's rise to the profile of "America's classical music." For historians like Grover Sales, the late-1960s and 1970s were "the dog days of jazz." Fusion jazz musicians were more concerned with selling records than producing music of any artistic value; experimentation with the materials and instruments of rock was simply an attempt "to recapture their dwindling audience." Albums like Bitches Brew "a heavily electronic rock creation" was seen as an attempt

\footnotetext{
6 Frank Tirro, Jazz: A History (New York: Norton, 1977), 358.

7 James Lincoln Collier, The Making of Jazz: A Comprehensive History (Boston, MA: Houghton Mifflin, 1978), 434-35.
} 
to pedal to "a new audience of young rock fans who had never paid the least attention to jazz in any form.",

The face of fusion jazz scholarship changed in the 1990s, however, with the publication of the first monograph-length historical work dedicated to the style: Stuart Nicholson's Jazz Rock: A History. ${ }^{9}$ This work provided a much-needed remedy to the underwhelming fusion jazz historiography of the previous decades, compiling a wealth of information on a wide array of fusion jazz musicians, many of whom had been ignored entirely in the previous literature. Also expanding the temporal scope of fusion from the late-1960s and 1970s, Nicholson considered the work of musicians from the early 1960s through to the 1990s, thus demonstrating the diversity of music and artists who associate, and are associated with, the stylistic label. Of particular note is Nicholson's attention to the function of the recording studio for fusion jazz musicians, which, although still relatively brief, offers a much more nuanced appraisal of its function within the style than earlier jazz historians had done. Ultimately Nicholson's macro-historical fusion jazz narrative would go on to function as an essential backdrop and point of reference for the music's micro-histories that later flourished.

Published soon after Jazz Rock and contributing further to the much-needed empirical work on fusion jazz was Paul Tingen's Miles Beyond: The Electric Explorations of Miles Davis, 1967-1991. ${ }^{10}$ Undertaking extensive interviews with dozens of the musicians who performed with Davis during the later half of his career, Tingen's work offers valuable insight into the creative processes of Davis as a fusion jazz musician. Several musicians describe in detail their experiences working with Davis in the recording studio and in concert. Tingen also offers his own critical appraisals of Davis's recorded output during this period, and contends that much of Davis's fusion jazz can be seen as naturally evolving from his work in the 1960s, a period in which he began experimenting with non-cyclical form, musical materials uncommon to jazz and electric instruments.

8 Grover Sales, Jazz: America's Classical Music (New York: Da Capo, 1984), 201-202. For exceptions to the generally inadequate coverage of fusion jazz during the 1970s and 1980s see Julie Coryell and Laura Friedman, Jazz-Rock Fusion, the People, the Music (New York: Dell Publishing Company, 1978); and Greg Tate, 'The Electric Miles', Down Beat, 50/8 (1983), 22-24, 54.

9 Stuart Nicholson, Jazz Rock: A History (New York: Schirmer Books, 1998).

10 Paul Tingen, Miles Beyond: The Electric Explorations of Miles Davis, 1967-1991 (New York: Billboard Books, 2001). 
Yet although the work of Nicholson and Tingen paved new ground in fusion jazz historiography, it was in fact several years early that fusion jazz first received attention in musicology. Gary Tomlinson played an understated yet no less crucial role in sparking this critical reappraisal of fusion jazz. ${ }^{11}$ While not a jazz scholar himself, Tomlinson's work signalled a first attempt to critically explore fusion jazz by applying to its study the postmodernist tools distinctive of musicology at the time. As part of a larger article concerned with the applicability of Henry Louis Gates's theory of Signifyin(g) to an understanding of artistic canon, Tomlinson deconstructed several criticisms that had been levelled at the fusion jazz of Miles Davis during the 1980s and early 1990s. ${ }^{12}$ In doing so, Tomlinson highlighted how these criticisms were over-determined by the logic of a jazz canon. He posited that these commentators, rather than trying to understand Davis's fusion jazz on its own terms, instead reject it on the grounds that it transgressed some of the basic tenants of the jazz canon: the abandonment of certain acoustic instruments and musical materials common to earlier jazz styles; gestures towards populism (and thus a move away from a high-art elitism); and ethnic and national markers of jazz such as Davis's inclusion of white and non-American musicians in his band. Tomlinson suggested that these commentators, in fixating on these apparent transgressions, all "reveal[ed] the same stark inability to hear Davis's fusion music except against the backdrop of what jazz was before it (and what it has since reverted to in the hands of some neo-bop technicians)." ${ }^{, 13}$ Instead of considering these critiques of Davis's fusion jazz as objective analytical descriptions of the music, Tomlinson claims they would be better understood as rhetorical gestures, which, through exclusion, aim to strengthen the identity and power of a jazz canon. ${ }^{14}$

11 Gary Tomlinson, 'Cultural Dialogics and Jazz: A White Historian Signifies', Black Music Research Journal 11/2 (1991), 229-264.

12 See Amiri Baraka, 'Where's the Music Going and Why?' in The Music: Reflections on Jazz and Blues (New York: William Morrow, 1987), 117-180; Stanley Crouch, 'Play the Right Thing', The New Republic (February 12), 30-37; John Litweiler, The Freedom Principal: Jazz After 1958 (New York: Da Capo, 1984); and Martin Williams, Jazz in Its Time (New York: Oxford University Press, 1989). Although these writers were working primarily within the space of jazz criticism, they are nonetheless representative of much of the sentiment of earlier and contemporaneous jazz historiography when it came to jazz styles that fell outside the canon. Thus Tomlinson's work can be understood equally as a critique of earlier historical writing on fusion jazz.

13 Tomlinson, 'Cultural Dialogics and Jazz', 251.

14 Tomlinson's writing on Davis's fusion jazz has prompted some rebuttal with the work of Eric Porter being of particular note. While accepting the contradictions that underlie some of critiques of 
Tomlinson's article was perhaps most important for the future of fusion jazz historiography in that it highlighted the general inadequacy and lack of rigor that typified the writing on fusion jazz up until that time. Many commentators, in becoming associated with the canon-building project of a growing neoclassicism in jazz, seemed unable or unwilling to explore deeply both the musical materials and the cultural significance of fusion jazz. ${ }^{15}$ Beyond his critique, however, Tomlinson's own alternative reading of Davis's music from the late-1960s and 1970s was also effective in setting a rigorous musicological study of fusion jazz in motion. To articulate the musical mixture distinctive of Davis's fusion jazz, Tomlinson drew on the theoretical concept of dialogical knowledge: "the building of a precarious discourse that never fully displaces the other discourses around it." ${ }^{\text {"16 }}$ To understand Davis's fusion jazz in terms of dialogical knowledge is to view it as a creative response to the changing musical environment that was evolving around him, and as a result of his interest in, and interaction with, developments in musical genre taking place in close proximity to the jazz world during the late-1960s and 1970s. Such a re-appraisal of fusion jazz proves both liberating and stimulating for scholars seeking to respond to the static portrayal of fusion jazz that had calcified in jazz historiography and criticism during the previous decades.

Tomlinson's association of dialogical knowledge with fusion jazz foreshadowed the work of fusion jazz scholar Kevin Fellezs. ${ }^{17}$ In his study of some of the music's leading figures-Tony Williams, John McLaughlin, Joni Mitchell and Herbie Hancock - Fellezs drew on a similar theoretical concept from literary criticism: the "broken middle", a concept devised by literary theorist Isobel

Davis's detractors, Porter sees it as nonetheless being important to situate these critiques within the broader cultural politics of jazz and African American culture and that it is "understood as part of a dialogue about the merits of black music and its potential role in social change." Eric Porter, "It's About That Time": The Response to Miles Davis's Electric Turn' in Miles Davis and American Culture, ed. Gerald Early (St. Louis, MO: Missouri Historical Society Press, 2001), 134.

15 John Gennari notes the important role played by writers Albert Murray and Stanley Crouch in Wynton Marsalis's critical success during the 1980s and 1990s. He also notes the work of critics Martin Williams and Gary Giddins in bolstering the popularity of Marsalis's neoclassical jazz. John Gennari, Blowin' Hot and Cool: Jazz and Its Critics (Chicago: University of Chicago Press, 2006).

16 Tomlinson, 'Cultural Dialogics and Jazz', 263.

17 Kevin Fellezs, Birds of Fire: Jazz, Rock, Funk, and the Creation of Fusion (Durham: Duke University Press, 2011) 
Armstrong. ${ }^{18}$ The broken middle of fusion jazz, Fellezs suggests, was a generically allusive liminal space created by musicians as they engaged with materials, creative processes, and cultural contexts from a range of popular, traditional and classical musical styles. ${ }^{19}$ These musicians "were motivated by the idea of innovative mixture rather than adhering to a modernist compulsion to produce sui generis originality."20 Fellezs saw this abandonment of generic continuity in favour of eclectic experimentation as a kind of critical praxis - specifically, a musical critique of genre and its growing hegemony over the production and reception of music during the late1960s and 1970s. While emblematic of the kind of re-appraisal of fusion jazz that Tomlinson espoused, Fellezs's rigorous attention to the music's social and cultural context situates his work more within cultural studies and critical theory than historical musicology or music theory. It does, however, provide a valuable historical narrative for later fusion jazz scholars to respond to.

Recent scholarship on fusion jazz also includes detailed description of musical material. Bob Gluck pays close attention to musical detail in his study of Herbie Hancock's early-seventies fusion jazz ensemble, the Mwandishi band. ${ }^{21}$ Gluck addresses Hancock's approach to melody, harmony and rhythm during this period, highlighting the pianist's use of tone clusters, harmonic abstraction and motivic development. One of the strengths in Gluck's analysis is that it situates Hancock's early-seventies music within the previous years spent he with Miles Davis's quintet of the mid- to late-1960s. Noting that while features such the instrumentation (electric pianos, synthesizers and African percussion instruments) and musical forms (freeform and ostinato-based performances) used in the Mwandishi band were radically different from early jazz styles, much of the material performed by Hancock had its origins in the his playing of the 1960s. In highlighting this stylistic continuity, Gluck goes against the grain of much earlier fusion jazz historiography, emphasizing those musical features that fusion jazz musicians had necessarily inherited from their time

18 Isobel Armstrong, The Radical Aesthetic (Oxford: Blackwell, 2000).

19 Fellezs, Birds of Fire, 8.

20 Ibid., 6.

21 Bob Gluck, You'll Know When You Get There: Herbie Hancock and the Mwandishi Band (Chicago: University of Chicago Press, 2012). 
working in earlier jazz styles, and, rather than severing fusion jazz from jazz's mainstream, draws it closer. ${ }^{22}$

\section{Fusion jazz and the recording studio}

While this recent scholarship goes a long way in extending the fusion jazz historiography of the 1970 s and 1980 s, it still pays only marginal attention to the role of the recording studio. However, two musicologists in particular have focused to the recording in fusion jazz. ${ }^{23}$ Steven Pond and Jeremy Smith both framed the issue of the recording process as central within the creative process of fusion jazz musicians. It is important to note that both scholars' attention to record production is framed by a methodological stance that foregrounds creative process. ${ }^{24}$ Whereas the evolving shape of fusion jazz historiography demonstrates a move from purely stylistic (that is, reductive) description of the music, Pond and Smith's work represents the first fusion jazz scholarship to thoroughly explore creative process as a means to formulate new definitions of fusion jazz.

For Steven Pond, fusion jazz should be understood as more than just jazz musicians' adoption of musical materials from concurrent musical genres; rather it

22 See also Lawrence Wayte, 'Bitches Brood: The Progeny of Miles Davis's Bitches Brew and the Sound of Jazz-Rock', (PhD diss., University of California, Los Angeles. 2007); and Jon Opstad, 'The Harmonic and Rhythmic Language of Herbie Hancock's 1970s Fender Rhodes Solos', Jazz Perspectives 3/1 (2009), 57-79.

23 This interest in recording technology is apparent in several recent articles associated with jazz studies more generally. See Gabriel Solis, “"A Unique Chunk of Jazz Reality”: Authorship, Musical Work Concepts, and Thelonious Monk's Live Recordings from the Five Spot, 1958', Ethnomusicology 48/3 (2004), 315-347. Katherine Tackley, 'Jazz Recordings as Social Texts', in Recorded Music: Performance, Culture and Technology, ed. Amanda Bayley (Cambridge, UK: Cambridge University Press, 2010), 167-186; and Tony Whyton, 'Acting on Impulse! Recordings and the Reification of Jazz' in Recorded Music: Philosophical and Critical Reflections, ed. Mine Dogantan-Dack (London: Middlesex University Press, 2008). See also Mark Katz, Capturing Sound: How Technology has Changed Music (Berkeley: University of California Press, 2004).

24 This attention to creative process reflects a broader methodological development to have taken place in jazz studies over the previous two decades, itself a product of the reappraisal of methodologies evidence in the burgeoning new musicology of the 1980s. See Ronald Radano, New Musical Configurations: Anthony Braxton's Cultural Critique (Chicago: University of Chicago Press, 1993); Paul Berliner, Thinking in Jazz (Chicago: University of Chicago Press, 1994); Ingrid Monson, Saying Something: Jazz Improvisation and Interaction (Chicago: University of Chicago Press, 1996); Norman Meehan, 'Creativity in Jazz' (PhD diss. New Zealand School of Music, 2014). John Brownell also offers an overview of jazz studies' growing interest in process-centred modes of analysis. See John Brownell, “Analytical Models of Jazz Improvisation”, Jazzforschung 26/1 (1994), 9-27. 
can be more usefully understood as an engagement in the creative processes peculiar to those genres, with a central process being record production: "the notion of fusion jazz...works most accurately not as a syncretic blend of parent styles, because the parentage is always slippery; [i]nstead, the style of production provides the most prominent unifying thread: an orientation of how to produce a recording." ${ }^{25}$ Similarly, Jeremy Smith sees record production as being necessarily accounted for in defining the emergence of fusion jazz. The fusion jazz of musicians like Miles Davis, Smith claims, needs to be understood as a reaction to "jazz's restrictive musical standards" and an indication of the bandleader's "desire for greater genre-based blending"; essential to this generic hybridity was Davis's adoption of "studio technologies and the phonography-centred aesthetic of the rock genre." 26

Fusion jazz musicians' new approaches to record production involved changes to the responsibilities and the creative reaches of the various participants in the recording studio. Pond notes that whereas traditionally the roles played by the musician and the producer were fairly distinct, with developments in fusion jazz, the musician-producer relationship took on a new shape. In interview with Pond, producer Dave Rubinson compares Hancock's production practices in the 1970s with how the pianist would have recorded with the likes of Rudy Van Gelder in the 1960s:

Rudy would record and say "this is it" when it was done. The next [Hancock] ever knew of it was when the record came out. So if anybody said, "You know, maybe a little more hi-hat," Rudy would say, "You gonna come here, you get my sound." So it was not fundamentally a creative process. They were really kind of cut off. And that was the old style. It was, "You go in and you record and you leave. You pick up some cash and you get the hell out of there." But what [the producers] do with the product is up to them. ${ }^{27}$

In contrast, fusion jazz musicians during the late-1960s and 1970s were taking a much more hands-on approach in the studio, engaging in the kind of creative processes that

25 Steven Pond, Head Hunters: The Making of Jazz's First Platinum Album (Ann Arbor, MI: University of Michigan Press, 2005), 154. For discussions of the record production processes distinctive of pop, rock, and funk, see Jake Brown, Behind the Boards: The Making of Rock 'n' Roll's Greatest Albums Revealed (Milwaukee, MI: Hal Leonard Books, 2012); Albin Zak, The Poetics of Rock: Cutting Tracks, Making Records (Berkeley: University of California Press, 2001); Anne Danielsen, Presence and Pleasure: The Funk Grooves of James Brown and Parliament (Middletown, CT: Wesleyan University Press, 2006).

26 Jeremy A. Smith, 'Sound, Mediation and Meaning in Miles Davis's A Tribute to Jack Johnson' (Ph.D. diss., Duke University, 2007), 124-25, 165. On the term phonography see Evan Eisenberg, The Recording Angel (New Haven, CT: Yale University Press, 2005).

27 Pond, Head Hunters, 123-24. 
had usually been the sole responsibility of the producer. Rubinson notes: "Herbie had access to the complete...creative process - including editing, mixing, splicing, layering — and he used it all." 28 Thus, the developments occurring in the recording studios of fusion jazz musicians were not simply just a matter of adopting new technologies, but also involved the musicians becoming more familiar with, and making use of, studio production techniques, which expanded the creative reach of the musician.

Elsewhere, it was the producers who were becoming more involved in the creative process of composition. For Miles Davis in particular, the changing ways in which musician and producer were interacting in the recording studio was fundamental to the recording process. Producer Teo Macero become renowned for his role in the post-production editing of the Davis's fusion jazz studio albums, and is widely considered an unofficial "co-composer" on albums like In a Silent Way, Bitches Brew, Jack Johnson and On the Corner. Supporting this view, Pond and Smith both compare Macero's use of tape-editing and manipulation with the practices of musique concrète composers. Pond notes how in producing Davis's fusion jazz studio albums Macero "craft[ed] sound recordings by splicing together pre-existing snippets of recorded material" a process the producer "likely would have encountered as a Julliard composition student in the fifties." ${ }^{29}$ Smith makes a similar assertion when he posits that Macero treated the master tapes from the late-sixties and earlyseventies studio sessions as "potential sound sources to [be] cut, spliced, and reorganised into the final tune" through "a rearticulation of the musique concrète principles Macero first encountered while under Varèse's tutelage in the 1950s."

As Pond and Smith both note, however, such approaches to record production signalled a radical departure from the recording methods common to jazz in the several decades leading up to the 1970s. Whereas earlier jazz recordings shared certain qualities with concert performance — both in terms of process and productthe new approaches to making records adopted by fusion musicians radically expanded the technical and musical boundaries of a studio-produced jazz album. Pond suggests that prior to the development of fusion jazz, technological limitations of

\footnotetext{
28 Pond, Head Hunters, 137.

29 Ibid., 98.

30 Smith, 'Sound Mediation and Meaning', 134.
} 
recording technology (referring to the use of two-track tape machines) simply demanded that musicians create recordings that closely resembled the creative conditions of concert performance; within these conditions, " the excitement, and implicit risk of irrecoverable error in one's improvisation were always present, much as in the live performance environment." ${ }^{, 31}$ Smith suggests that as a result many observers came to feel that the "responsibility of recording technology [was] simply to capture that which the musicians [were] already playing...From this perspective, the unaltered, unmediated instantiation of group interaction via a single, complete performance of a tune was the primary authenticating gesture for a jazz recording.

Where fusion jazz musicians departed from conventional approaches to recording was in their move away from the desire to represent live performances. Smith posits that unlike "traditional jazz listeners [who] continued to value the idea of transparent documentary representation, [fusion jazz musicians] had broadly accepted studio technology as a viable mode of musical production based on a different aesthetic standard from live musical performance." 33 Accordingly, for observers critical of fusion jazz musicians' new approach to recording, what seemed to be at stake was more than just the basic stylistic features of the mainstream jazz (4/4 swing and acoustic instruments), but an aspect of the music that defined it as an artistically legitimate cultural practice: the interactive process of group improvisation. ${ }^{34}$ As Pond suggests, these critics felt that a "reliance on technology impinged on or even removed in-the-moment improvisation opportunities or disguised a lack of mastery." ${ }^{, 35}$ In the jazz world, music that was understood as "manufactured moments" was equated with a musician's inability to perform with the

31 Pond, Head Hunters, 121-22.

32 Smith, 'Sound, Mediation and Meaning', 113-14. For examples of this viewpoint see Michael Chanan's comment: "The aim of jazz is to achieve a sense of the spontaneous through sophisticated and controlled improvisation, to be a music which never stands still; the record is a means to an end." Michael Chanan, Repeated Takes: A Short History of Recording and its Effects on Music (London: Verso, 1995), 19. See also A. J. Millard, who describes jazz as a music that was "not written down but drew energy from the spontaneous expression of the musicians. The record was the only way to save it." A. J. Millard, America on Record: A History of Recorded Sound (Cambridge, NY: Cambridge University Press, 1995), 248.

33 Smith, 'Sound, Mediation and Meaning', 125.

34 See Paul Berliner, Thinking in Jazz; Ingrid Monson, Saying Something.

35 Pond, Head Hunters, 125. 
same degree of skill as those musicians who recorded using more "transparent" production methods. ${ }^{36}$

\section{The studio-stage interrelationship in fusion jazz}

By adopting a methodological stance that foregrounds creative process, Pond and Smith have been able to look beyond fusion jazz's most obvious stylistic deviations from the mainstream of jazz and highlight fusion jazz musicians' new approaches to recording production: a merging of the interactive, improvised performance processes of earlier jazz styles with the phonographic techniques of rock and musique concrète. Yet, due to the privileging, and prominence, of live performance in jazz culture, it is no surprise that both scholars have also given some consideration to an interrelationship between the fusion jazz created in the recording studio and on the concert stage. There is, however, no consensus between Pond and Smith as to whether such an interrelationship exists, or whether this interrelationship is reciprocal.

Pond posits that when it comes to the fusion jazz of Herbie Hancock there is in fact an interrelationship between the creative processes of the studio and on the stage. He notes that in the lead up to the recording of Head Hunters, Hancock and his band would alternate between rehearsals (which were recorded) and concert performance: jams were recorded and reworked in the studio, "then tested in front of live audiences for further refinement." ${ }^{, 37}$ Hancock's own comments on his band's concert performances leading up to the recording Head Hunters speak further to this process: "[concerts] helped us shape the music, to refine what it was that we were doing. Playing it in front of a live audience like that before recording it. Then we went back into the recording studio and recorded it." 38 Similarly, wind-player Benny Maupin tells Pond: "Those gigs that we would do on the weekend enabled us to develop a way of playing through the forms of the tunes and just doing it all live. Because that was an important part of what we wanted to capture: the live playing., ${ }^{, 39}$ For Hancock and

\footnotetext{
36 Pond, Head Hunters, 122.

37 Ibid., 141.

38 Ibid., 142.

39 Ibid.
} 
his band during the early-1970s working in the recording studio was thus not an insular process, but rather one that drew on many aspects of concert performance and saw record production became integrated into the compositional process.

Smith, in his study on Davis's fusion jazz, sees little room for the possibility of an interrelationship between the recording studio and the stage, which contrasts notably with Pond's description of Hancock's work. Indeed, the differences between the studio and the stage, for Smith, are far more notable:

Davis understood the studio to be a different creative environment from a live concert, and he maintained distinct ideas about what was musically appropriate in each setting. For Davis, live concerts facilitated a sense of both immediacy and finality through the particular modes of group interaction and improvisation that they made possible. In the studio, Davis equally valued interaction and improvisation, but in the service of creating blocks of sound that could then later be overdubbed, spliced, or otherwise edited in their use as source material for future tunes or albums. ${ }^{40}$

Smith seems to suggest here that for Davis, the interactive creative process he engaged in during concert performance was made immediately accessible to his audience. In contrast, in the case of his studio recordings, while similar interactive creative processes were being engaged in by the musicians, they were engaged in with a different purpose in mind: to later select the most desirable moments from the recorded performance and then arrange these moments into the final product. Smith addresses this issue in more detail, noting:

The studio allowed for several takes of a given solo that could then be edited either to shorten a solo that had gone on for too long or to combine together the best portions of two or more takes of a solo. In a live concert, however, there was no opportunity to go back and try a solo again or shorten a solo that had extended beyond an engaging length. ${ }^{41}$

The effect of these apparent creative opportunities and limitations, Smith suggests, had both negative and positive effects. In the studio, while the musicians had the opportunity to record several takes, and have these takes edited, they were also faced with the fact that the recording would be available for listening long after the recording was made - theoretically for eternity. In contrast, the performance in concert was far more ephemeral, the sounds heard once and remaining only in the

40 Smith, 'Sound, Mediation and Meaning', 50.

41 Ibid., 46. Perhaps an exception to this would be Davis's Live/Evil: an album, which through postproduction tape editing, combined live recordings with material recorded in the studio. 
participant's memories. ${ }^{42}$ Nevertheless, because the concert performance did not allow for retakes, interruptions or restarts, there was greater pressure for the musicians to "get it right first time."

Another factor that Smith identifies as contrasting between Davis's studio and concert creative process was the sonic and visual "lines of communication," which would have effected the group's musical interaction. Smith notes that "in a studio, the availability of sound monitors and the creation of a controlled aural space helped to guarantee that each musician would be able to hear all the other musicians."43 Offering a contrast to this ideal sonic environment for performance, Smith quotes pianist Chick Corea reflecting on performing in concert with the Davis band in 1970: "When Keith [Jarrett] and I played live, there was really no communication. . . I could never hear what Keith was playing and I doubt Keith ever heard a note I was playing. So it was hard to really play something together.",44

When it came to visual interaction, however, Smith sees a reversal in the performance parameters: the limitations that were often placed on musicians' visual communication in the recording studio, often attributed to sound baffles or having the musicians positioned in different rooms, would have made gestural interaction difficult. In contrast, "the band's ability to arrange their physical layout on the concert stage would have helped to ensure open sightlines, thereby facilitating the visual aspects that contribute to a successful musical experience." ${ }^{45}$

While Smith acknowledges that some commentators in discussing earlier jazz styles have questioned the apparent distinctions between studio and concert performances ${ }^{46}$ he nonetheless finds the distinctions between studio and concert

42 As Robert Philip notes, "In a live performance, the pressure is on the performer to please one audience; a recording, however, will remain in existence potentially forever-the performer thus feels the pressure to please all of posterity" Robert Philip, Performing Music in the Age of Recording, 43. Concert performances are, however, becoming increasingly susceptible to being captured by "bootleggers." Bootleg recordings and other semi-professional recordings (such as those made by bands themselves in which a tape machine would be plugged directly into the concert mixing desk) have become more widely available in recent years; several of these recordings have been important sources in my own research and have allowed a fuller account of what Davis's concert performances were like.

43 Smith, 'Sound, Mediation, and Meaning', 47.

44 Ibid.

45 Ibid.

46 Smith cites Gabriel Solis's general caution that "one should be aware of the limitations of approaching jazz recordings as though they were conceptually independent of live performances for 
performance in Davis's fusion jazz to be significant:

Though the basic values of musical interaction and group improvisation remain the same for Davis in both contexts, the vastly different expectations he held for how that interaction would be organised in these two venues demonstrate that, for Davis, there were key differences between musical creation in the studio and in a concert setting. ${ }^{47}$

For Smith, the presence of improvised musical material in both studio and stage performance settings seems to be not enough to suggest a definitive interrelationship in terms of creative process. What is more significant is the way in which Davis "organized" this material, which Smith claims contrasts notably between the two creative spaces.

Thanks to the recent work of the several scholars addressed above fusion jazz is no longer a jazz style marginalized in music historiography. Taken togetherNicholson's and Tingen's rectification of the dearth of empirical scholarship on fusion jazz, Tomlinson's critique of fusion jazz's reception during the 1980s and early-1990s along with his reappraisal of Davis's fusion jazz, Fellezs's carefully nuanced historical narrative that foregrounds the social and cultural context of fusion jazz's production and reception, Gluck's analytical attention to the musical detail of fusion jazz and his situation of this music within the musical techniques common to earlier jazz styles, and Pond and Smith's articulation of the centrality of the recording process in the activities of fusion jazz musicians - this literature has significantly raised the bar, and set the stage, for future musicological studies of fusion jazz. Yet while the rigor of this work should prove extremely encouraging for future fusion jazz scholars, it does leave virtually unanswered the question of live performance in fusion jazz-a question that I see as being necessary to address if it is hoped that fusion jazz is to be better understood as being part of, or existing in relation to, a jazz tradition.

In this thesis I will be building primarily on the work of Pond and Smith and their approaches to considering the ways fusion jazz musicians like Miles Davis drew on creative processes from the stage in developing new methods of record production

\footnotetext{
either musicians or audiences.” Solis, “"A Unique Chunk of Jazz Reality”, 336.

47 Smith, 'Sound, Mediation, and Meaning', 51 (footnote 21).
} 
in the studio. While highlighting the significant effect the recording studio had on fusion jazz musicians in their development of new approaches to improvisation and composition, neither scholar explores in any detail the possibility of these developments informing the work of fusion jazz musicians in concert. Pond's observations on the ways in which concert performance informed the creative process of Hancock and his band in the recording studio do at least point to a studio-stage interrelationship. Yet is it not possible that such an interrelationship could occur in reverse- from the studio to the stage? Similarly, Smith's distinctions between Davis's creative process in the studio and on the stage are valuable when aiming to develop a more nuanced understanding of fusion jazz, given that they highlight the fact that the music was produced and received in different creative spaces. Yet does it then follow that Davis's reconceptualization of music-making demonstrated in his late-1960s and early-1970s studio-produced albums would have been forgotten by the bandleader as soon as he set foot outside the recording studio? It is these questions that I attempt to begin answering in the remainder of this thesis. 


\section{Chapter Two:}

\section{The Creative Process in Davis's Fusion Jazz Studio Albums}

\section{Reorientating composition and improvisation in the recording studio}

To assert that fusion jazz saw the sudden arrival of recording technology's impact on the creative process of jazz musicians would be slightly disingenuous. In fact, ever since the earlier years of recorded jazz, the particular technology available to musicians had a notable effect on their approaches to composition and improvisation. For instance, as Mark Katz points out, because of the technological limitations faced by jazz musicians making records during the late-1910s and 1920s "concision became a virtue, if not a defining trait, of the music. How early jazz is understood, therefore, is often a function of its phonographic preservation." ${ }^{48}$ Historian, Burton Peretti, notes the restrictions that early recording technology placed upon jazz musicians during the pre-electric era, "the technical limitations [being] a major frustration to musicians, and the main hindrance to effective recording." 49 Yet in other ways, the particularities of recording technology could be used in the musician's favour, especially with the advent of electric recording. Duke Ellington stands as a fascinating example of a jazz composer whose creative process was informed by the peculiarities of early electric recording technology. Historian, Harvey Cohen, notes that during the 1920s and 1930s "while other band recordings tended to carelessly blend the sounds of the orchestra into a flat, indistinct midrange, Ellington's 1926-33 output featured a wider dynamic range of sound and clearer delineation of the various instruments." Similarly, Ellington biographer, A. H. Lawrence, points to Ellington's careful consideration of microphone placement within the studio as contributing to the greater tonal quality of mid- to late-1920s recordings. ${ }^{51}$ These comments suggest that Ellington's considerations of electric recording technology's peculiarities informed his creative process. By composing and arranging performances that allowed for

\footnotetext{
48 Katz, Capturing Sound, 76-77.

49 Burton W. Peretti, The Creation of Jazz: Music, Race and Culture in Urban America (Urbana, IL: University of Illinois Press, 1992), 161.

50 Harvey Cohen, Duke Ellington's America (Chicago: University of Chicago Press, 2010), 67.

51 A. H. Lawrence, Duke Ellington and His World: A Biography (New York: Routledge, 2001), 95.
} 
certain tones and timbres to be picked up more effectively than other large band recordings Ellington was able to maximise their impact on listeners. It could well be argued that Ellington's signature sound as a composer and arranger- to use the individual and unique sounds of certain members of his band to create his own musical identity — was shaped, in part, by his time producing records.

Throughout much of Davis's early career, too, the effect of recording technology is evident in his approaches to composition and improvisation, his use of recording technology during the 1950s and 1960s often demonstrating a wilful attempt to exploit its creative possibilities. During the mid-1950s, Davis can be seen as maximizing developments in recording and playback technology: "Bag's Groove" from the album of the same name extends over ten minutes and includes extended solo improvisations (during this period many jazz recording artists failed to take advantage of the greater playback times made available through new technology). Davis' growing command of the recording studio's creative parameters is also apparent in his work of the late-1950s, evidenced in his experimentation with modal jazz and his move away from prescribed cyclical form in Kind of Blue's "Flamenco Sketches." ${ }^{, 52}$ Further, throughout the 1960s, unusual formal structures became a prominent feature of his recorded repertoire, pieces such as "Freedom Jazz Dance" and "Orbits" from Miles Smiles being of particular note. ${ }^{53}$

Yet it was not until the late-1960s that this creative symbiosis of technology, composition and improvisation became most pronounced - the same time his music started becoming identified with the burgeoning fusion jazz style. Davis biographer Ian Carr's commentary on "Country Son" from Miles in the Sky and "Mademoiselle Mabry" from Filles de Kilimanjaro offers a useful way into discussing Davis's changing creative processes during this period: "The old relationship with popular or standard songs - no matter how tangential — had disappeared...In his recordings from now on, Miles wouldn't start with the idea of set pieces; instead he would simply explore some fragmentary elements and edit them into a cohesive piece of music

\footnotetext{
52 See Ashley Kahn, Kind of Blue: the Making of the Miles Davis Masterpeice (New York: De Capo Press, 2000).

53 See Keith Waters. The Studio Recordings of the Miles Davis Quintet, 1965-68 (New York: Oxford University Press, 2011).
} 
afterwards. ${ }^{, 54}$ Carr points out that by the late-1960s Davis had reached a kind of tipping point in the creative processes of record production: instead of entering the studio with a set of pre-composed pieces to use as vehicles for improvisation — as had been common practice in jazz-Davis and his ensemble, would develop musical material in the studio through a combination of activities that resembled composition and improvisation, while all the time keeping the tape-machine rolling; later Davis and his producer Teo Macero would edit the recorded material to construct the final version of each piece. Importantly, this new creative process set aside the use of cyclical song form, which had a far-reaching effect on the broader creative processes of his musicians: now, not only were the musicians contributing as either improvisers or composers, but through a combination of these two activities facilitated by the tape machine, they were engaging in a radically new means of creating music. Between 1969 and 1972 Davis recorded several studio albums that would follow this kind of method, in doing so reorientating the relationship between composition and improvisation common to jazz and challenging the conventions of jazz record production.

One of the major changes in Davis's creative process during the late-1960s and early-1970s saw composition, an activity that had traditionally preceded the recording of improvised performance, become integrated with the recording and improvising process itself. Drummer, Jack DeJohnette, recalls that, throughout the sessions as Davis's band rehearsed and developed materials, "we were creating things and making things up on the spot, and the significant thing was that the tape recorder was always rolling and capturing it." ${ }^{, 55}$ Instead of recording pieces in complete takes, Davis and his studio-band would capture fragments of material, whether it was a melodic theme, a riff, or a solo or group improvisation. As drummer Lenny White remembers:

During the [Bitches Brew] session we'd start a groove, and we'd play... and then Miles would point to John McLaughlin and John would play for a while, and then Miles would stop the band. Then we'd start up again and he'd point to the

\footnotetext{
54 Ian Carr, Miles Davis: The Definitive Biography (London: HarperCollins, 1998) 243. Keith Waters also addresses Davis's changing approach to composition and improvisation in the recording studio during the mid- to late-1960s. He writes "it is likely that the second quintet studio recordings helped the musicians conceptualise ways for building compositional structures that avoided chorus structure improvisation.” Waters, The Studio Recordings of the Miles Davis Quintet, 1965-68, 238.

55 Tingen, Miles Beyond, 66.
} 
keyboards, and someone would do another solo. All the tracks were done in segments like that. ${ }^{56}$

The breakdown from traditional approaches to composition and improvisation in the studio was so great that it was not unusual for the distinction between rehearsal and performance to seem entirely opaque. As bassist Harvey Brooks noted: "Often we didn't know whether we were rehearsing or recording, but Miles had a policy to record everything." 57 Thus, regardless of whether the musicians were intending to be setting their playing to recording, the fact that they were being constantly recorded meant that anything played, regardless of its perceived value at the time, would be captured and made available for later listening.

As many of the musicians from Davis's recording ensembles were accustomed to conventional jazz recording practice, the particular ways in which the bandleader approached the production of his studio albums would have seemed like a radical departure from the norm. Compared to record production practices common to jazz in which complete takes were made from start to finish, this fragmented approach would surely have been remarkably disconcerting. The inability of Guitarist, John McLaughlin, to comprehend what was to come of the 1969 In a Silent Way sessions is expressed in a comment he made to Herbie Hancock, and goes some way in demonstrating his feeling of disorientation. Hancock remembers McLaughlin asking him after the three-hour session: "was that any good what we did? I mean, what did we do? I can't tell what's going on!" The pianist recalls replying "John, welcome to a Miles Davis session. Your guess is as good as mine. I have no idea, but somehow when the records come out, they end up sounding good." 58 Benny Maupin shares Hancock's feeling of disconnection between the recording process and his reception of the album in its final form. The wind-player recalls hearing the 1970 Bitches Brew for the first time on the radio:

I was going crazy. I was saying, 'What is that?" I said, "It sounds familiar, but I didn't know what that is.' And finally...the [DJ] says, 'Well, that's the new Miles Davis recording, Bitches Brew.' And that's when I first heard it...I had no idea that that music sounded so beautiful. Because I couldn't tell anything during the

\footnotetext{
56 Tingen, Miles Beyond, 65.

57 Ibid.

58 Ibid., 59.
} 
recording sessions. ${ }^{59}$

Echoing Maupin, keyboard player Joe Zawinul remembers:

I didn't really like the sessions at the time...I didn't think they were exciting enough. But a short while later I was at the CBS offices, and a secretary was playing this incredible music. It was really smoking. So I asked her, "Who the hell is this?" And she replied, "It's that Bitches Brew thing." I thought, "Damn, that's great." 60

While each of these musicians found the recording process disorientating and somewhat unsatisfying, on hearing the recordings in their final form, they were incredibly surprised by how their work had taken shape; what they had performed in the studio made sense to them in the context of the album's totality.

As might be expected, however, Davis's unique approach to record production was not always met as positively. Paul Buckmaster, who composed material for the 1972 On the Corner, was taken aback when he realised how loosely his pre-composed material would be used in the actual production of the album. Buckmaster recalls:

I had given the musicians my scores and had sung my phrases to the drummers, and they started playing them. Miles said, 'Good, leave it like that,' but I wanted to say, 'That's not what I mean!' The problem was that instead of playing the grooves I'd written, they played the fills, and they became the groove. This is why I find the end result unfree and restricting. Although I like steady groove...the rhythm was never intended by me to be as obsessively repetitious as it became. ${ }^{61}$

Anticipating his pre-composed work would be reproduced and interpreted in a fashion more common to jazz performance practice, Buckmaster's expectations were dashed when Davis picked only fragments of the scores to be played-he concluded that $O n$ the Corner was his "least favourite Miles album." 62

Surely, however, one of the most extreme examples of Davis's ability to musically disorientate his musicians is evidenced in Dave Liebman's first musical encounter with the bandleader for the recording of On the Corner. Liebman recollects arriving late to the session, having been called in last minute to replace one of Davis's regular studio musicians. He describes what happened as he entered the studio:

I remember it was exactly 12:30, and I walked into the corridor between the booth

\footnotetext{
59 Pond, Head Hunters, 135.

60 Tingen, Miles Beyond, 72-73.

61 Ibid., 134.

62 Ibid.
} 
and the recording studio with doors on either side and I looked into the studio...He saw me in the window of the door, and he signalled me to come in. So I went right in...Half the instruments are directly electronic, so you don't hear them live in the studio. There were no earphones for me. I just walked in. They started playing and all I heard was a kind of "chick a chick" kind of beat....I heard a little bit of somebody chugging away on the piano, but I heard mostly silence. You know how weird it is in a studio when you take your earphones off. You hear all these little sharpie sounds, but no music, and I couldn't hear anything. I couldn't hear the key. I didn't know what was going on...Then he cues me. With his fingers he made a motion for me to play the saxophone, and he pushed me to his mic. So I had to start playing. ${ }^{63}$

Not only was Davis restricting Liebman's access to all the musical materials that would usually undergird jazz improvisation (form, meter, rhythm, etc.) but he was also cutting the saxophonist off from virtually all the other sonic content being recorded. Perhaps unsurprisingly, Liebman, like Buckmaster, did not respond positively to On the Corner's release. ${ }^{64}$

In general, however, the musicians who recorded with Davis greatly appreciated his new approach in the recording studio. Bassist Dave Holland commented:

One of the things that created the sound of the [late-sixties and early-seventies] studio recordings was that we were all trying to figure out what was going on...this created a certain space. It wasn't that it was tentative, but when you really know a piece of music, there's a tendency to over play it sometimes. If you don't know the music, you're more careful and searching in your playing. ${ }^{65}$

Holland's comments suggest that Davis's approach to record production caused the musicians to work in ways that demanded a heightened degree of both care and exploration; subtracting the usual musical parameters required a greater degree of awareness (both of what one was playing and what others were playing) as well as further testing of novel musical ideas.

Buckmaster, despite his particular quibbles with On the Corner nonetheless seconds Holland, seeing Davis's restriction on the amount of prescribed material for each session as an effort "to catch freshness and unpredictability, catch the musicians without their 'commenting minds.' Otherwise they fall into clichés...Miles was

\footnotetext{
63 Larry Fisher, Miles Davis and David Liebman: Jazz Connections (Lampeter, United Kingdom: Mellen Press, 1996) 81-82.

64 Tingen, Miles Beyond, 137.

${ }^{65}$ Ibid., 57.
} 
keeping them on their edge, on their toes, and directing them into unexplored territory." ${ }^{\prime 66}$ Buckmaster sees Davis as wanting to push his musicians out of their habitual musical practices to produce material that was unexpected. Describing Davis's effort to "catch" his musicians' activities is perhaps indicative of the fact that throughout the entire proceedings the tape machine was capturing everything being played. This perspective goes someway in reframing Liebman's first recording session with Davis, which at first glance may seem to verge on the sadistic, or just simply the irreverent. Yet in disorientating Liebman and isolating virtually all the musical material an improvising musician would expect to be playing in response to, Davis pushed the saxophonist to improvise in a way that he may not have were this material provided; Davis seems to have been pushing for something unexpected (the fact that Liebman's solo features in the opening moments of On the Corner may say something about how Davis valued this particular performance). What is more, accounting for the surprise shared by several of Davis's musicians on first hearing the final version of Bitches Brew may indeed suggest that Davis succeeded in pushing them beyond what they would have played in a more comfortable and familiar musical setting and demonstrate that during the sessions he was able to provoke them to make music while silencing their inner critical voices, or, their "commenting minds."

\section{Post-production tape editing and the construction of musical form}

So far, in addressing Davis's new approaches to record production during the making of his first several fusion jazz studio albums, I have been focusing on the roles played by Davis and his musicians as they broke from the norms of jazz composition and improvisation in the recording studio. Yet without the crucial input of Davis's producer Teo Macero, it would have been impossible for these new approaches to be explored. After all, it was Macero who was responsible for piecing together the various fragments of recorded material into the individual pieces and the final commercially released album. Were Davis to have been working in the studio without the knowledge that the material being recorded was to be later cut up and rearranged by Macero, the kind of experimentation with integrating composition and

\footnotetext{
66 Tingen, Miles Beyond, 135.
} 
improvisation would not have been possible. However, when it comes to defining the kind, and degree, of creative agency held by Macero in the production of Davis's studio albums, it is difficult to reach a consensus. As Jeremy Smith has highlighted, Macero's own perspective on his role as producer and composer during the making of Davis's fusion jazz studio albums has changed over time. Whereas during the late1960s Macero described the final editing of Davis's albums as a joint venture (shared between himself and Davis), as time passed his recollections of this period tended more towards foregrounding his primacy in the editing process. ${ }^{67}$ This inconsistency in Macero's accounts makes clarifying his exact role in the process of producing Davis's studio albums somewhat challenging. Accordingly, rather than exploring in greater depth the particular creative processes engaged in by Macero I turn here instead to look at the reception, both critical and scholarly, of Macero's work. It is in this reception that understandings of Davis's studio-produced fusion jazz seem to have become slightly unclear, which has resulted in Davis's unique approach to composition and improvisation becoming somewhat obscured.

Despite the fact that Macero's post-production editing was complicit in Davis's development of new processes of composition and improvisation in the recording studio during the late-1960s and early-1970s, much of the discourse that surrounds Macero's role tends to centre upon the his production qua composition. The result is that often the way in which Macero's production facilitated the composition and improvisation of Davis and his ensemble is overlooked, and in some cases significantly marginalized. Journalist Philip Freeman's discussion of Bitches Brew is exemplary of this kind of commentary: "Miles and Teo abandoned the idea of 'honesty' in studio recordings. They chose to assert that the record was the record, a work unto itself; if a listener felt like hearing interactive performances by a group of musicians, well that's what concerts are for." ${ }^{68}$ Freeman equates Bitches Brew's departure from the documentary-style aesthetic of earlier jazz recordings with a lack of interactivity amongst the musicians performing on the album; for a recording to transcend a representation of a performance and become an autonomous work it must necessarily disassociate itself from the individuals involved in its creation, and the

67 Smith, 'Sound, Mediation and Meaning', 141-51.

68 Philip Freeman, Running the Voodoo Down: The Electric Music of Miles Davis (San Francisco: Backbeat Books, 2005), 87. 
methods used to create it. Similarly, Stuart Nicholson, in commenting on Davis mid1960s and early-1970s studio albums, writes: "Such studio creations demand to be heard on their own terms...since the important thing about art is not the means used to achieve an end, but the end it achieves." ${ }^{\prime 69}$ While Nicholson seems intent on celebrating, and drawing attention to, the uniqueness of Davis's fusion jazz studio albums, in doing so he promotes a critical interpretation of the album that risks undermining the particular activities of the musicians who create the music.

The comments of Freeman and Nicholson make for interesting comparison to those of Steven Pond and Jeremy Smith who, as previously noted, both relate Macero's production of Davis's studio fusion jazz albums to the practices of musique concrète composers. ${ }^{70}$ If, as Freeman and Nicholson suggest, Davis's studio-produced fusion jazz albums are to be received as musical works in their own right, and as such, no-longer documents of live musical performance, then they would compare fittingly to the tape-based works created by musique concrète composers who were concerned with making music that appeared to the listener to have no worldly source. Pierre Schaeffer described such "originless" manipulations of sound recordings as acousmatic music - perhaps the most autonomous of all musics. Brian Kane, describing Schaeffer's musical conception, writes: "Schaeffer was trying to differentiate his approach from traditional practices of musical composition bound to the note." It was "a music that began with sounds recorded from the world and sought to perceive in them (and abstract from them) musical values." ${ }^{71}$ If the likes of Bitches Brew is to be treated as an autonomous artwork, with the post-production methods used to construct them playing a pivotal role in this reading, then such albums and their creation would surely be comparable to Schaeffer's Cinq Études de Bruits.

Yet if we consider both the type of material that Macero was editing in postproduction and the particular impact his approach to post-production had on the musical activities of Davis and his ensemble, then it is not the similarities but the differences between the activities and intentions of a composer like Schaeffer and a

\footnotetext{
69 Nicholson, Jazz Rock, 98.

70 Pond, Head Hunters, 98; Smith, 'Sound, Mediation and Meaning', 134.

71 Brian Kane, The Sound Unseen: Acousmatic Sound in Theory and Practice (New York: Oxford University Press, 2014) 17.
} 
producer like Macero that are most apparent. First, it is important to note that the material Macero was editing was clearly distinguishable to an audience familiar with jazz performance practice as material produced by a group of improvising musicians. What is more, despite the, at times, quite complex editing of Macero, the recording as it stands in its final version nonetheless is still clearly representative of musical improvisation. If we then consider the aesthetic goal of musique concrète of drawing an audience's attention away from a sound's originary source, such a logic of creation and listening surely does not reflect the experience of most Bitches Brew audiences. The album clearly projects a jazz aesthetic in the degree and kind of improvisation it contains. Jazz is generally understood, both from the perspectives of production and reception, as operating outside the aesthetic parameters of autonomous music; it is not just the music itself that is of significance, but the very process of creating that music that is often the object of primary concern and interest. ${ }^{72}$ Thus, it would be difficult to disregard the way in which Davis's fusion jazz studio albums were created, partly because the "ends"- - how the album is received in its final for-is inherently tied up with the "means" of production: a process of group improvisation.

Macero's direct impact on the kind of musical activities he was capturing on record is also more indicative of a distinction from, rather than a similarity to, musique concrète. Given that the prevalence of improvisation - and not just improvisation based on pre-composed material but improvisation that was part of the compositional process - in the recording sessions of Davis's studio fusion jazz albums was facilitated by Macero's post-production editing, we cannot extract his impact from the creation of the material he was recording. As such, the material he would then use to reconstruct the final forms of Davis's studio albums were in no way neutral to him; he was complicit in their creation. In other words he does not deny the

72 On live jazz performance Scott DeVeaux writes: "there is an element of choice that is present at every moment, and something about knowing that, while listening to a performance, makes it particularly special." Scott DeVeaux, 'This is What I Do' in Art from Start to Finish: Jazz, Painting, Writing, and Other Improvisations, ed. Howard S. Becker et al (Chicago: University of Chicago Press, 2006), 118-125 [122]. See also Andrew Kania's distinction between "active performance" and "phenomenal performance." Citing Jerrold Levinson, Kania sees active performances as the understanding of performance as a process; in contrast, phenomenal performance is understood more in a reductive sense in which (quoting Levinson) "the thing primarily judged seems to be product rather than process, achieved result, rather than activity of achieving it." Kania suggests jazz is generally treated as active performance. Andrew Kania, 'Works, Performances, Recordings: Classical, Rock, Jazz" in Recorded Music: Philosophical and Critical Reflections, ed. Mine Dogantan-Dack (London: Middlesex University Press, 2010), 3-21, [13]. 
agency of the producers of the sound source, but rather frames it through editing together the album's final version. Indeed, due to the particular formal freedoms that Macero's editing allowed to Davis and his band the creative agency of each musician was heightened.

How can it be, then, that despite the obviousness of the degree of improvisation involved in Davis's fusion jazz studio albums, many commentators on the music tend to highlight Macero's activities in these album's production, while implicitly disassociating his activities from those of the musicians? One possible reason, I suggest, is to do with broader conceptions of recording technology and how these conceptions framed understandings of musical creation, particularly activities like composition and improvisation. As Pond and Smith both discuss, in the jazz world prior to fusion jazz's rise, recordings were generally seen as a medium for representing composition and improvisation, and more specifically, capturing as transparently as possible the group interactive performance process-one of jazz's most celebrated and defining practices. Given the prevalence of this view on the recording in jazz, a shift in perspective that would include recording technology as playing a part in the creative process of musicians would be quite a leap outside the norms of jazz. Such a shift in perspective may, however, be the kind of conceptual leap required to thoroughly acknowledge the fact that during the late 1960s and early1970s Davis did not use the recording studio as a means to recreate musical performances, but as a tool for creating them. By thoroughly integrating recording technology into the compositional and improvisational process, it becomes a crucial creative tool, losing its meaning as a device intended simply for documentation.

To better understand how this misconception of the central creative function the recording studio played for Davis, it is worthwhile briefly considering the bandleader's use of the recording studio in light of recent theories of technological determinism and volunteerism. ${ }^{73}$ Timothy Taylor's account of this theoretical binary

73 Timothy Taylor, Strange Sounds: Music, Technology and Culture (New York: Routledge, 2001), 26-38. On technological determinism and volunteerism see also Wiebe Bijker, Thomas P. Huges, and Trevor Pinch, eds., The Social Construction of Technological Systems: New Directions in the Sociology and History of Technology (Cambridge, Mass." MIT Press, 1987); Ruth Finnegan, Literacy and Orality: Studies in the Technology of Communication (Oxford, England: Basil Blackwell, 1988); Bruce Bimber, 'Karl Marx, and the Three Faces of Technological Determinism', Social Studies of Science 20/1 (1990), 333-351; and Donald MacKenzie and Judy Wajcman, The Social Shaping of Technology: How the Refrigerator Got Its Hum, second ed. (Buckingham, England: Open University Press, 1999). 
is a useful starting point. He describes proponents of voluntarism as holding the view that "technology is a tool that people use, nothing more, and is thus essentially neutral" whereas for determinists, "technology is assumed to transform its users directly... it changes us, perhaps more than we change it." 74 Rejecting "hard" notions of determinism (which privileges structure) and voluntarism (which privileges agency), Taylor concludes nonetheless that there can be no straightforward synthesis of these two positions. ${ }^{75}$ Rather, he sees structure and agency functioning in a dynamic relationship with the other, which he describes in terms of practice theory. ${ }^{76}$ Negotiating this theoretical tension, Taylor uses two terms to describe the ways in which humans produce, and interact with, technology: schemas and resources. "Schemas are those rules that are largely unspoken by technology's users, thereby allowing for some degree of determinism." In contrast "a resource refers to what we do with it - that is, what is voluntaristic."77 In Taylor's view, technologies as resources are understood as essentially neutral, with the potential to be used in any way willed by its user; technologies are only deterministic as schemas, the meanings that come to be associated with them being the determining factor in how they are used, and how this use is understood. Accordingly, the more a technology's user is able to looking beyond its expected use, the closer they will come to using that technology as a neutral resource.

This conception of technology provides a useful starting point for thinking in greater theoretical depth about Davis's use of the recording studio during the late1960s and 1970s. Adopting Taylor's framework, Davis can be seen to have departed from the conventional schemas associated with the resource of the recording studio, while adapting schemas associated with concurrent popular and art musics. Davis's "misuse" of the recording studio suggests that the socially deterministic (which, although still framing understandings of his use of the recording studio) did not determine his use of it; rather his departure from the schemas of the recording studio

\footnotetext{
74 Taylor, Strange Sounds, 26.

75 Ibid., 37.

76 See Sherry Ortner, Making Gender: The Politics and Erotics of Culture (Boston: Beacon Press, 1996).

77 Taylor, Strange Sounds, 37. Taylor derives his terms of "schema" and "resource" from their use by William H. Sewell. See "A Theory of Structure: Duality, Agency, and Transformation,” American Journal of Sociology, 98 (1992).
} 
as defined by the dominant jazz aesthetic of the time indicates it can be used as a resource outside of the preconceived norms of its use. Davis's use of the recording studio can thus be seen to demonstrate its flexibility as a technological resource; it is the social construction of the recording studio as a technology of musical recreation that can obscure its particular use by Davis as a tool of musical creation.

While I have noted that neither the inclusion of record production in the creative process, nor Davis's rejection of cyclical form, were necessarily unique to fusion jazz, I have tried to show that both manifested in some distinctive ways in Davis's fusion jazz studio albums. As demonstrated in the commentary of the musicians who worked with Davis in the studio during the late-1960s and early1970s, the bandleader's approach to record production veered away from earlier methods of making jazz records. By using the tape-machine to capture all of the musicians activities in the studio with the intention of later reconstructing the recorded material in post-production, Davis was able to reject cyclical form-both as a structure to guide composition and as a means for improvising — and further integrate improvisation, particularly group improvisation, into the composition process. In developing this method of record production, Davis disrupted the expected patterns of creative processes associated with jazz performance and forced his musicians into musical situations that they were unfamiliar with; their response was to create music that they potentially would not have done had they been working within the usual musical parameters of jazz practice.

Davis's studio-produced fusion jazz of the late-1960s and early-1970s demonstrates a unique response to larger changes to musical conception that had taken shape in the jazz world during the 1960s. In doing so, he enhanced one of the key features of jazz - group improvisation - foregrounding it in the compositional process. Given the success of this new musical approach, then, how could this newly developed conception of musical creation have shaped his approach to leading a band in a concert setting? It is this question that I address in the following two chapters. 


\section{Chapter Three:}

\section{The Rhythm Section Cut}

\section{"Rated X" and the rhythm section cut}

On November 22, 1974 Columbia released Get Up with It, an album containing material that Davis had produced in the recording studio between May 1970 and October 1974. Compiled from pieces recorded over a four-year period, the album consisted of a diverse range of music, capturing dozens of musicians playing together in an array of ensemble combinations, and demonstrating a host of different recording technologies and methods. One of the most astonishing pieces on the album, however, is "Rated X." Of all the studio recordings made by Davis during the late-1960s and 1970s, it is "Rated X" that perhaps best demonstrates Davis's departure from the traditional live performance aesthetic of jazz recordings. Remarkably, it is also the recording that first garnered critical commentary positing an interrelationship between the studio and stage in Davis's fusion jazz.

Like many of Davis's fusion jazz studio recordings, "Rated X" was in part a product of Teo Macero's distinctive approach to post-production tape-editing. Creating the final piece from material that had been recorded on two separate occasions, Macero combined an undated recording of Davis - not on trumpet, but YC45 electric organ - with a recording that captured Davis's current rhythm section playing together on September 6, 1972. While the amalgamation of recorded material from two or more different sessions was not unique within Davis's fusion jazz oeuvre, what does make Macero's editing of "Rated X" singular is that rather than splicing together disparate recordings side by side, Macero overlaid each recording, in a sense “overdubbing" Davis's organ playing onto the rhythm section performance. Further, what makes Macero's editing on "Rated X" even more striking is the way in which at certain unexpected moments throughout the piece, he isolates Davis's organ playing, cutting the rhythm section from the mix and leaving the electric organ to be heard unaccompanied, only to then suddenly drop the rhythm section back into the mix.

Given the explicitly studio-produced quality of "Rated X" it should come as quite a surprise that the recording has been singled out by several commentators as the one fusion jazz studio recording made by Davis that bears some discernable 
interrelationship to his live performances of the period. John Szwed, commenting on Dark Magus suggests that Davis "used hand signals to stop the band from time to time much as the engineer had occasionally erased the band in "Rated X.",78 Frank Bergerot, also addressing Dark Magus, interprets the ensemble as being "periodically interrupted by the bandleader's gesture to stop" which he suggests is Davis's "way of recreating the on-off effect in live performance." ${ }^{, 79}$ And similarly, Richard Cook, discussing a later recording of Davis in concert during 1975, observes that "Both men [saxophonist Sonny Fortune and guitarist Pete Cosey] play on over the rhythm section dropouts", which he infers "were introduced on 'Rated X.", 80

In making these comparisons between the editing of "Rated X" and Davis's live performance practice, these writers are referring to one of Davis's bandleadership strategies developed during the early- to mid-1970s. Davis would use hand signals in concert performances to cut the rhythm section, leaving the featured soloist to continue unaccompanied. ${ }^{81}$ As a listener, the effect is astonishing. Often these cuts are applied during passages of intense energy and volume; the sudden absence of sound has the potential to create a kind of auditory "after-glow" in which the mind can struggle to comprehend the sudden change in dynamics. ${ }^{82}$ For Davis's band, the rhythm section cuts could be just as unexpected. Bassist Michael Henderson has commented that during concert performances Davis could "move his finger, or nod

78 Szwed, So What: the Life of Miles Davis (New York: Simon and Schuster, 2002), 338.

79 Franck Bergerot, We Want Miles: Miles Davis (New York: Skira Rizzoli, 2010), 177. While Bergerot does not mention "Rated X" in name, I surmise that he is referring to the track in the way he describes the "on off effect," which seems an apt description for the effect created by Macero in his editing of "Rated X." Although similar cuts can be heard in studio recordings as far back as February 1970 ( in "Willie Nelson" from the Jack Johnson sessions, and in "Chieftain," an August 1972 recording made around the time of On the Corner's production) "Rated X" was the first recording publicly released to feature this post-production effect.

80 Richard Cook, It's About That Time: Miles Davis On and Off the Record (London: Atlantic, 2005), 258.

81 While Cook refers to these as "rhythm section dropouts" my preference is to describe them as rhythm section "cuts" as doing so draws attention to the fact that they are instigated by Davis as bandleader during live performance.

82 Joanna Demers comments on Filament I, a work by experimental artists Otomo Yoshihide and Sachiko M., seem salient here. Demers writes: "The most shocking moments are between tracks, especially when the loud, pain inducing sounds are suddenly followed by silence, a silence that the mind attempts to fill with remembered noise just as the eyes will retain a retinal image of a bright light, exacts its own sort of discomfort." Joanna Demers, 'Materialism, Ontology, and Experimental Music Aesthetics', in Tomorrow is the Question: New Directions in Experimental Music Studies, ed. Benjamin Piekut, (Ann Arbor, MI: University of Michigan Press, 2014), 267. 
his head, and that would be it...You'd better watch and listen, because he could do it at any moment." ${ }^{, 83}$ From around mid-1973, Davis's direction of unexpected rhythm section cuts become a regular part of his performance practice, and is prevalent in his recorded concert performances through until mid-1975. ${ }^{84}$

The above comparisons between the studio-produced rhythm section cuts in "Rated X" and Davis's on-stage directions lead us some way in appreciating a studiostage interrelationship in Davis's fusion jazz, yet they lead us only so far. They point us decisively in the direction of a studio-to-stage creative trajectory within Davis's fusion jazz, notably, by giving a certain amount of consideration to creative process; it is not only the sounds themselves that are highlighted in these comments, but also the way these sounds are produced - not just the "what" but also the "how." Yet on closer inspection these comments nonetheless fall short in asserting a direct interrelationship between the creative processes of the studio and the stage. As a closer inspection of the above comments reveals, rather than defining a causal association between the activities of Macero in the studio and the activities of Davis on the stage, what each writer seems to be suggesting instead is that Davis's bandleadership strategies on stage were an attempt to recreate the effect of Macero's editing. If we were to actually compare the activities that produced "Rated X" and Davis's activities as a bandleader in concert performances, it is some much the similarities but the differences that would be most striking: whereas Davis's on-stage directions are effecting musical interaction amongst all the musicians involved, Macero's essentially undermine such interaction. Given the music of Davis's concert performances was created in a shared spatio-temporal setting, his on-stage directions affected direct interaction amongst the musicians performing. In stark contrast, Macero's editing of "Rated X" pieced together two disparate recordings; in this setting there was no real-time musical interaction between Davis on organ and his rhythm section.

The question might then be: do these differences necessarily preclude the potential for any kind of studio-to-stage creative trajectory in Davis's fusion jazz? I

83 Tingen, Miles Beyond, 156. Davis had other ways of directing his band between pieces and section in concert performance, including musical signposts he'd create with his trumpet, which he was using frequently in his early fusion jazz concerts during the late 1960s. See Tingen, Miles Beyond, 115-116.

84 For an example see 'Miles Davis Live in Vienna 1973 Stadthalle Ganze Konzert', < https://www.youtube.com/watch?v=wOA9_TdRFt4\&spfreload=10>30 March 2015. The rhythm section cuts are most striking at around twenty minutes into the video. 
suggest not. While further attention to the creative processes that produced "Rated X" may not bring us much closer to conceptualizing a meaningful studio-stage creative interrelationship, it can nonetheless provide a useful starting point for such an interrelationship. As I argue in this chapter the possibility of a studio-to-stage creative trajectory in Davis's fusion jazz is plausible if we follow three preliminary lines of thinking: first, we need to take the step of looking beyond Macero's tape editing on "Rated X" specifically as the primary influence on Davis's live performance stage directions, and instead conceive of these stage directions as being informed more generally by Macero's tape editing techniques throughout Davis's fusion jazz oeuvre; second, we need to consider not only the products of Macero's actions-what his tape-editing sounded like in the final commercial recording - but also what these actions facilitated during the production of the album, particularly in the recording studio; and third, we need to look beyond the rhythm section cuts reductively and consider what Davis's use of them could facilitate in a concert performancespecifically, what kinds of compositional and improvisational activities they would allow Davis as bandleader and his ensemble as improvising musicians.

From this critical vantage point, I claim in this chapter it is indeed possible to see how Davis's rhythm section cuts were informed by his experiences working in the recording studio. Beginning with an analysis of Dark Magus, I examine several of the rhythm section cuts applied by Davis throughout the Carnegie Hall concert. I focus on two distinctive types of the rhythm section cut: the transitional-cut and the solo-cut. I then suggest how these rhythm section cuts reflect the kind of changes to Davis's conception of composition and improvisation as discussed in Chapter Two.

\section{The rhythm section cut in Dark Magus}

Before turning to examples of Davis's use of the rhythm section cut, it is worth noting the discrepancy between titles listed on the commercial release of Dark Magus and the pieces being played. The titles listed on the album were more or less extraneous: they were assigned to each piece by CBS/Sony Japan producer, Tatsu Nosaki, prior to the album's release in 1977, around four years after the concert was recorded. ${ }^{85}$ These titles actually obscured the fact that all of the pieces recorded on Dark Magus were

85 Szwed, So What, 338. 
based on material that was by this stage in the Davis band's mid-1970's lifespan very familiar to the band.

\begin{tabular}{|l|l|}
\hline Piece - title in CD release & Piece - alternative title \\
\hline CD 1 & Set 1 \\
Moja (Part 1) & Turnaroundphrase \\
Moja (Part 2) & Tune in Five \\
Wili (Part 1) & Funk-Prelude Part One \\
Wili (Part 2) & For Dave-Mr Foster \\
\hline CD 2 & \\
Tatu (Part 1) & Set 2 \\
Tatu (Part 2) & Funk-Prelude Part One (Reprise) \\
Nne (Part 1) & Calypso Frelimo [incomplete] \\
Nne (Part 2) & Ife [incomplete] \\
& Turnaroundphrase \& Tune in Five \\
\hline
\end{tabular}

FIGURE 1.

Transitional-cuts: Davis used this type of rhythm section cut to signal formal transitions. Just like most of Davis's concert performances during the mid-1970s, the pieces performed by Davis and his band on Dark Magus do not follow prescribed formal structures but instead consist of brief melodic themes and various instrumental solos. Along with the themes, the pre-composed material consists of bass and guitar riffs, and particular drum patterns. The solos could be thought of as modal, and are most often based upon single tonal centres. Davis often uses the transitional-cut as a way to signal one of three transition types: from theme to solo (or vice versa, from solo to theme); between solo sections; and between individual pieces (see FIGURE 2).

These transitional-cuts are clear examples of an approach to constructing and manipulating musical form in real-time as they provide Davis, as bandleader, a means for authorial control over the broader formal shape of each piece and the performance as a whole. Accordingly, in looking to define a studio-to-stage creative trajectory, the transitional-cuts may seem to offer the most appropriate example with which to demonstrate a clear correlation between the creative processes of the recording studio and the concert stage. However, as I suggested in Chapter Two, what is perhaps most remarkable about the creative processes - specifically Macero's editing - that shaped Davis's fusion jazz studio recordings is not the construction of complete musical structures from fragments of recorded performances, but the way in which 


\begin{tabular}{|c|c|}
\hline Transition Type & Occurrence \\
\hline Theme to solo (and vice-versa) & $\begin{array}{l}\text { "Ife" } \\
1: 53 \text { - theme (Davis [trumpet]; Liebman) } \\
\text { to solo (Liebman) } \\
\text { "Calypso Frelimo" } \\
2: 43 \text { - solo (Gaumont) to theme (Davis, } \\
\text { organ) }\end{array}$ \\
\hline Solo to solo & $\begin{array}{l}\text { "Turnaroundphrase" } \\
\text { 8:15 - Davis (trumpet) to Cosey } \\
\text { "Tune in Five" } \\
\text { 9:27 - Davis (trumpet) to Cosey and } \\
\text { Mtume (collective improvisation, hand } \\
\text { percussion) } \\
\text { "Funk-Prelude Part One" } \\
\text { 11:28 - Liebman to Davis (organ) } \\
\text { 12:55 - Davis (organ) to Mtume (drum } \\
\text { machine) } \\
\text { "Ife" } \\
\text { 4:23 - Liebman to Gaumont } \\
\text { 11:21 - Gaumont to Davis (trumpet) }\end{array}$ \\
\hline Piece to piece ${ }^{86}$ & $\begin{array}{l}\text { "Tune in Five" to "Funk Prelude Part } \\
\text { One" } \\
\text { "Funk-Prelude Part One" (reprise) to } \\
\text { "Calypso Frelimo" }\end{array}$ \\
\hline
\end{tabular}

FIGURE 2.

post-production editing allowed Davis and his band to develop new approaches to

86 Unfortunately, due to the editing that done to produce the Dark Magus as an album, the transition between "Calypso Frelimo" and "Ife" is not included in the album's final edit. I should note that there have been many times throughout my research where I was prepared to pay handsomely for the complete recordings of this concert, but these have not been made commercially available. Apart from the obvious edits made and the end of "Calypso Frelimo" where a fadeout has been effected in post-production, and in the opening of "Ife," I have been able to identify at most three other edits, interestingly all of which were in the opening track Turnaroundphrase: at 5:08, 10:10, and potentially one at 12:18. My conclusion, however, was that after comparing Dark Magus with other recordings of Davis's mid-1970s concerts in which there was no editing of the performances, I decided that Dark Magus was still in most ways highly exemplary of the kind of performances Davis was undertaking during this period, and the edits did not obscure some of the most essential creative practices of Davis and his band. 
improvisation and composition. As I discuss below, it is another type of rhythm section cut heard in Dark Magus, the solo-cut, that I see as a better example of a studio-to-stage creative trajectory in Davis's fusion jazz.

Solo-cuts: In contrast to the transitional-cut, which provides a means for Davis to shift the ensemble between sections of piece or whole pieces, the solo-cut is used within individual sections of each piece. At what seem to be random moments during the extended improvisations of lead soloists, Davis would direct the rhythm section to suddenly stop playing, leaving the soloist to continue, either unaccompanied or with minimal rhythmic support from one of the rhythm section players. Although the solocut is used in five of the eight pieces on Dark Magus (see FIGURE 3.), I choose to focus here on the solo-cuts that occur in two particular pieces: "Tune in Five" and the reprise of "Funk-Prelude Part One." These pieces provide contrasting examples of

\begin{tabular}{|c|c|}
\hline Piece & Occurrence \\
\hline "Tune in Five" & $\begin{array}{l}1: 43-1: 55 \text { (Liebman) } \\
3: 45-4: 04 \text { (Cosey) }\end{array}$ \\
\hline "Funk-Prelude Part One" & $\begin{array}{l}5: 26-5: 35 \text { (Davis - organ) } \\
10: 20-10: 22,10: 23-10: 33 \text { (Liebman) }\end{array}$ \\
\hline $\begin{array}{l}\text { "Funk-Prelude Part One" } \\
\text { (Reprise) }\end{array}$ & $\begin{array}{l}7: 31-7: 44,7: 47-8: 18 \text { (Gaumont) } \\
8: 50-9: 09,10: 12-10: 23 \\
\text { (Lawrence/Liebman) } \\
11: 35-11: 49 \text { (Lawrence) } \\
15: 34-15: 55 \text { (Lawrence) } \\
16: 23-16: 27,16: 35-16: 39,16: 40-16: 42 \\
\text { (Cosey) }\end{array}$ \\
\hline "Ife" & $7: 55-8: 03$ (Gaumont) \\
\hline $\begin{array}{l}\text { "Turnaroundphrase/Tune in } \\
\text { Five" (Reprise) }\end{array}$ & $\begin{array}{l}1: 40-1: 46,2: 12-2: 34 \text { (Lawrence) } \\
6: 00-6: 19 \text { (Gaumont) }\end{array}$ \\
\hline
\end{tabular}

FIGURE 3. 
how Davis was able to use the solo-cut as a strategy for foregrounding the improvised material of his lead soloists.

"Tune in Five" opens with a hectic groove generated by the ensemble's rhythm section. Drummer Al Foster, responsible for providing the rhythmic foundation, creates a sense of metric ambiguity by oscillating between a 5/4 rockorientated groove and a 4/4 four-to-the-floor pattern in which the quarter note of the $5 / 4$ pattern becomes the half note in the $4 / 4$ groove. Alongside Foster, bassist, Michael Henderson, pedals a low E-flat; rather than playing in tight synchronisation with Foster, Henderson floats underneath the drummer's churning groove. Pete Cosey on cowbell and Mtume on drum machine can just be heard above Foster and Henderson. Although the percussionists' presence is not foregrounded, the material they produce contributes noticeably to the total effect of the rhythm section's groove, enhancing its unsettled and frantic nature.

The introductory groove of "Tune in Five" is quickly followed with the solo of saxophonist, Dave Liebman. Beginning around the half-minute mark, Liebman develops his improvised melody by alternating between strong melodic ideas and "sheets of sound" built off triadic and pentatonic material in a post-Coltrane vein. ${ }^{87}$ Working with and against Henderson's continuous E-flat pedal tone, Liebman shifts back and forth between consonant and dissonant tonalities, moving between an E-flat minor tonality and G and A triads (the III and \# IV of E-flat, respectively). Liebman rarely locks in rhythmically with the 5/4 groove played by Foster, choosing to float over the rhythm section's frenzied groove instead.

Rhythm guitarist, Reggie Lucas in accompanying Liebman begins with a series of shimmering sustained chords (played with a pitch modulator pedal — either a flanger or chorus), which oscillate in consonance and dissonance. By 1:07, however, Lucas's phrases become shorter and more rhythm-orientated as he joins Foster in generating the foundational groove. With Foster moving from the hi-hats to crash cymbal at 1:25 the colour of his constant quarter-note brightens, growing in intensity. As Liebman's improvised phrases increase in register, Lucas's bubbling riff, which

\footnotetext{
87 "Sheets of sound" is a term coined by Ira Gitler to describe the impression of Coltrane's rapid melodic phrases. See Lewis Porter, John Coltrane: His Life and Music (Ann Arbor: University of Michigan Press, 1998), 132-34; and Ekkehard Jost, Free Jazz (New York: De Capo Press, 1974), 99-100.
} 
blends with the background percussion-work of Cosey and Mtume, becomes more apparent in the mix. After the first one minute and forty seconds, through a combination of drums, bass, rhythm guitar, sax and percussion, the band has created a considerable sense of harmonic, rhythmic and metrical tension.

All of a sudden, the rhythm section's churning groove fizzles out and within a couple of seconds Liebman is left to play virtually alone, accompanied only by the light, barely audible percussion work of Mtume: the first solo-cut of "Tune in Five" has just been signalled by Davis. Without the support of the rhythm section Liebman takes a decidedly different improvisational approach, playing phrases that contrast noticeably from the first minute of his solo: there is a change in tonality with the saxophonist playing a clearly defined G, the major 3rd of E-flat, signalling the first definitive move to a major tonality (it is in fact the only point in his solo at which he makes a strong assertion of the major tonality in relation to the pedal tone); rhythmically, his phrases become sparser. When combined with the rhythm section's sudden absence, these changes in Liebman's melodic and rhythmic approach create a floating feeling; in being suddenly freed from the rhythm section's relentless groove, Liebman seems to become detached from the tonal and rhythmic foundation that dominated in the opening section of "Tune in Five."

Within seconds, however, the weightlessness of Liebman's playing ends suddenly as Davis singles the return of the rhythm section and the saxophonist is forced to re-enter the ensemble's "gravitational pull." The power of the groove that Liebman had been briefly spared from seems to have compounded and as the rhythm section re-enters the saxophonist is met with a rush of pent-up energy even more ferocious than prior to the solo-cut: Foster continues to play heavily on the crash cymbal and momentarily pedalling the quarter note on his hi-hat from around the twominute mark, sounding almost like a crazed version of Tony Williams from Davis's Second Quintet; Henderson's pedal tones become more frequent; and Cosey's cowbell becomes more persistent. There is still an ebb and flow in the density of Foster's playing as he moves between unrelenting and washy; yet instead of shifting between the 5/4 and 4/4 meter, he maintains the groove in 5/4 with the underlying 3/4 meter established by the pattern being played on the kick drum. Lucas's accompanimental riffs become more prominent, continuing to reinforce the tempi and meter grounded by Foster and placing further emphasis on the underlying 3/4 meter. Even though the groove is still metrically ambiguous, and there is no clear sense of 
rhythmic interlocking between Liebman as soloist and Foster as accompanist, the two musicians seem to interact more through the density of their phrases. Liebman's oscillation between sparse and dense melodic ideas becomes more drawn out as he continues to float above the groove of Lucas and Foster, while still projecting his own sense of rhythmic security. ${ }^{88}$

Around 2:50, Liebman's solo draws to a close; within a few seconds guitarist Pete Cosey begins his solo. After several short melodic phrases Cosey begins the sheets of sound so distinctive of his unique improvisational approach. Unlike the melodic contrast of Liebman's solo, created by alternating his phrases between sparse and dense melodic material, Cosey's solo is very active both rhythmically (the extreme tempi of his phrases) and harmonically (regular shifts between "inside" and "outside" harmonic structures); apart from the several sustained notes high in the guitar's register, the melodic content of Cosey's solo can barely be discerned. During Cosey's solo, the rhythm section continue on in much the same manner as in their support of Liebman creating a seamless blend between the two.

At 3:45 Davis signals the second solo-cut of "Tune in Five". As the rhythm section suddenly falls silent, Cosey seems to relish the dynamic and timbral space made available to him, continuing his sheets of sound, but creating more variety in the frequencies being manipulated with his effects pedals. ${ }^{89}$ Cosey's approach to the solocut contrasts Liebman's: whereas Liebman seemed more to pull back and relax, the energy projected by Cosey increases. Perhaps in response to Cosey's continued energetic playing through into the solo-cut, Davis allows the guitarist both more time to play unaccompanied and rather than gesturing for a sudden return of the rhythm

${ }^{88}$ Lawrence Wayte, in comparing free jazz with fusion jazz posits the former as not usually being pinned down to one shared sense of pulse, tempo, or meter, while the later as having a much clearer rhythmic centre. Wayte cites David Ake's description of Ornette Coleman's 1959 "Lonely Woman" recording: "Through Coleman's challenge to the hegemony of "the form," Haden and Higgins were free to investigate new, non teleological, less rhythmic strategies. No longer was it necessary for the rhythm section to outline rhythmic-harmonic cadences at eight-bar intervals." This performance of "Tune in 5" stands as an exception to Wayte's observation. See Wayte, Bitches Brood, 34; David Ake, 'Re-Masculating Jazz: Ornette Coleman, "Lonely Women" and the New York Jazz Scene in the Late 1950s', American Music 16/1 (1998), 25-44.

89 During this passage of Cosey's solo it sounds as if he is using a foot control pedal similar to Wah, although the effect is slightly different: not only does the pedal modulate the frequency of the signal but also the volume, yet in reverse to a regular volume pedal: the volume dips at the same point at which the frequency modulation is at its peak, while the volume is greatest in the reverse position; in other words, as Cosey filters the high frequencies he increases guitar's output, while in filtering the low frequencies he decreases the guitar's output. 
section, allows for a more gentle re-entry, the drums and bass and drum machine gradually fading in. Noteworthy here is the way in which the rhythm section seems to mirror the melodic and rhythmic ambiguity of Cosey's playing during the solo-cut as they re-enter without setting up a clearly-defined groove: Foster keeps mostly to cymbals and kick drum, and Mtume, returning to drum machine, continues to play grooves at hyper-tempi, creating a heightened sense of rhythmic ambiguity.

During the first four-and-a-half minutes of "Tune in Five" Davis applies only two solo-cuts. Yet in doing so he can be seen to facilitate a considerable amount of musical contrast: a shift from a minor to major tonality; an increase and decrease in the intensity of rhythm section accompaniment; and changes in the interaction between the soloist and the accompanists. What is more, each solo-cut is approached differently, by Davis, the soloists and the accompanists: the first solo-cut Davis signal is ended suddenly, while the second involves a gradual re-entry of the rhythm section; Liebman approaches the solo-cut by reducing energy, whereas Cosey increases the energy during his solo-cut; and the rhythm section make distinctive changes in intensity following the first solo-cut, which in turn informs Liebman's solo, while mirroring Cosey's playing in the second solo-cut re-entry.

A contrasting example of Davis's use of the solo-cut in Dark Magus is heard during the reprise of "Funk-Prelude Part One", the opening piece of the second set. It is at this point in the concert where featured guest musicians, Dominique Gaumont and Azar Lawrence, first appear. ${ }^{90}$ It would be fair to say that, in using the solo-cut during this piece, Davis does not make life easy for the two newcomers. Not having been able to develop the same kind musical familiarity shared amongst the core ensemble of Davis's band, the task of having to respond assertively to the solo-cuts would have been made all the more challenging.

90 Davis's inclusion of these two guest musicians in 1974 Carnegie Hall concert bears similarities to the last minute additions of "ring-ins" to some of Davis's studio albums recorded during this period. It was tempting to address this in more detail here as it suggests an influence of creative process developed in the recording studio being carried over onto the concert stage; however, because Dark Magus is an oddity in this sense - it is one of the only recordings made of a live Davis concert from this period which includes musicians other than the core band members - it therefore does not represent his common approach to concert performance during the mid 1970s. What complicates this issue further is the fact that despite there being a consensus among several scholars that Azar Lawrence debuted with the Davis band at the March 30 Carnegie Hall concert, there is some disagreement as to when Dominique Gaumont first played with Davis: Paul Tingen and John Szwed both infer that he first played with Davis March 30, while Liebman and Nicholson claim that his first performance with the band was several months prior (although neither specify an exact date). Tingen, Miles Beyond, 155; Szwed, So What, 337; Nicholson, Jazz Rock, 125; Dave Liebman, Dark Magus [liner notes] Europe: Columba/Legacy, [1997] 1977. 
Beginning his guitar solo around 2:27, guitarist Dominique Gaumont plunges into a heavily distorted blues-inflicted improvisation, buoyed by the rhythm section's heavy, rollicking groove. This groove is not without out its subtleties, however: while, on first listening, both drummer and bassist may seem to be playing fairly regular accompanimental figures (Foster a heavy $4 / 4$ rock beat and Henderson a short bass riff using the B-flat minor pentatonic) closer attention reveals that there is actually significant variation in what they are each playing, both rhythmically and harmonically (Foster's variation of the kick and snare, and Henderson's use of passing notes); in addition, Cosey's rhythmically-loose cowbell patterns could potentially be unsettling for a soloist. After around five minutes of high-energy improvisation, ${ }^{91}$ Davis signals a solo-cut at 7:31, leaving of the rhythm section only Cosey to continue on cowbell. Gaumont hesitates for several seconds, but re-enters, rushing through some stock phrases, which lack the kind of rhythmic or melodic control he demonstrated during the previous several minutes of improvisation, and sounding far less confident than Liebman and Cosey during their unaccompanied solos in "Tune in Five." At the end of a string of hurried blues phrases, as if out of ideas, Gaumont shifts into the upper register of his guitar to play a long sustained note, which seems to hang in mid air. As this note gradually fades, Davis signals the rhythm section to re-enter at 7:44. Gaumont responds accordingly, scrambling even higher into his guitar's register to play several squealed, distorted notes. Within two bars, however, Davis cuts the band again, this time leaving Gaumont to play unaccompanied for around half a minute. Although much of what is played during this passage resembles a similar kind of melodic approach as the previous solo-cut, Gaumont does begin exploring some interesting ideas that extend beyond conventional musical material, involving the extended manipulation of feedback from his guitar. His playing between 7:52 - 7:58 and 8:10-8:18 is perhaps most exemplary of this approach, further reflecting the Hendrix influence.

Shortly after Davis signals the return of the rhythm section at 8:18, saxophonist Azar Lawrence, the second guest musician, begins his solo. Lawrence does not seem to get off to a strong start, failing to develop any strong melodic ideas; when compared to the cogency of the solos on "Tune in Five" the saxophonist seems

91 Gaumont's playing is clearly influenced by Jimi Hendrix: there are some striking similarities evident in this passage, the manipulation of feedback, distortion, pitch and tone between 5:355:45 being particularly comparable to Hendrix's guitar playing on "Machine Gun" from Band of Gypsys: 
well out of his depth. Davis, rather than giving Lawrence some time to try and settle into the groove and develop some stronger ideas, cuts the rhythm section thirty seconds into the saxophonists solo, leaving him to flounder with only the accompaniment of Cosey's cowbell. Faced with his first solo-cut of the performance, Lawrence, much like Gaumont, seems to freeze up at first, leaving a couple of seconds of silence, to then suddenly start playing several garbled phrases. ${ }^{92}$ Quite surprisingly, within seconds, Liebman joins Lawrence, starting by mirroring his counterpart's phrases and entering into a duet of sorts with the guest saxophonist. What was looking to be a train-wreck of a solo is quickly transformed into a moment of rousing dialogic exchange between the two improvisers. Within seconds of Liebman's entry, almost as an indication of approval, Davis signals the rhythm section to return. The dialogue between Liebman and Lawrence is suddenly given a huge boost of rhythmic energy, both soloists responding with more confident improvised phrases.

In contrast to "Tune in Five" Davis uses the solo-cut three times instead of two during the reprise of "Funk-Prelude Part One". Apart from the first brief cut, the second two are considerably longer than those used in "Tune in Five." Davis seems to draw these cuts out so as to put greater pressure on the soloists to improvise more exciting material—which (unlike Liebman and Cosey) Gaumont and Lawrence struggle to do at first attempt. Nonetheless, Davis allows each soloist enough time to create something that contrasts with what they had been previously playing: for Gaumont this meant moving away from blues-based phrases into more tonallyambiguous and sonically-experimental material; and for Lawrence, this involved engaging in a duet with Liebman, in which both saxophonists played with an increased level of energy and conviction.

What is particularly noteworthy about the use of the solo-cut in each piece is the way it is able to enhance the ensemble's improvisation on the most basic of precomposed material: for "Tune in Five" a pedal tone and rhythmic groove modulating between 5/4 and 4/4; and for the "Funk-Prelude" reprise a brawny rock beat and a straight-forward blues bass riff. The solo-cuts not only create significant dynamic shifts in the performance, but they also provide the musicians with formal signposts-

92 Lawrence's influences seem to be drawn from the jazz avant garde of the 1960s, his harsh tenor tone and honked, aggressive phrases bearing some resemblance to the likes of Albert Ayler and Archie Shepp. 
as spontaneous as they are-around which to make changes in their improvisational approaches and create considerable musical development. As such, these examples show just how distinct the solo-cut is from the transitional-cut: rather than signalling transitions between prescribed sections, the solo-cut provides a space for the featured soloist to take control of the piece's direction. Accordingly, the creative agency is shared evenly between bandleader and bandmember. Even though Davis, as bandleader, is responsible for initiating the solo-cuts and for deciding at what point in a given section their use could be most effective, it is the bandmembers, both soloists and accompanists, who decide just how to react to the solo-cuts, both during and following their signalling.

\section{The solo-cut as a real-time compositional strategy}

We can start to think about the rhythm section cut within a larger context by considering it in comparison to the unaccompanied lead breaks common to earlier jazz styles. While the solo-cuts discussed above would to most listeners sound utterly unique, there is no doubt they bear a notable resemblance to the breaks heard in earlier jazz styles, from the earliest jazz recordings through to the $1960 \mathrm{~s} .{ }^{93}$ If we want to better understand the place of fusion jazz within the stylistic development of jazz more generally and conceive of it as a part of, or in relation to, a jazz tradition, then it is worthwhile paying attention to how Davis's use of the rhythm section cut compares to the lead break made renowned by the likes of jazz figureheads Louis Armstrong, Charlie Parker and John Coltrane. ${ }^{94}$

Maintaining the methodological stance I have adopted throughout this thesis, it seems to me that the similarities between the lead break of earlier jazz styles and Davis's rhythm section cuts are more likely to be conceived of when primary attention is paid to each as aesthetic object. When comparing these various breaks in

93 See for example Armstrong's "Potato Head Blues", Parker's "Night in Tunisia", and John Coltrane's "Moment's Notice."

94 For examples of how the break has been treated as a metaphor for the assertion of individual identity see Ralph Ellison, 'The Charlie Christian Story', in Shadow and Act (New York: Vintage Books, 1972), 233-240; Albert Murray, 'Improvisation and the Creative Process', in The Jazz Cadence of American Culture, ed. Robert G. O’Meally (New York: Columbia Unversity Press, 1998), 111-113; Fred Moten, In the Break: The Aesthetics of the Black Radical Tradition (Minneapolis: University of Minnesota Press, 2003). 
terms of process, however, it is the differences that become most apparent. First, the break in earlier jazz styles was contingent on the form of the improvisational vehicle: breaks were usually limited to a two or four bar section of the form. Accordingly, such breaks were pre-determined in the form; the ability to extend the form by soloing over the break for as long as desired was prohibited by the formal structure undergirding the improvisation. Second, it was not uncommon for the particular lead breaks being played to have been pre-composed. ${ }^{95}$ In contrast, Davis's rhythm section cuts were applied spontaneously, and rather than being part of a pre-composed form, were instead dependant on to the indeterminacy of the forms Davis and his band were playing. Second, the breaks extended for a range of different measures, and the number of measures for each break was also undetermined. And third, the soloist was not always playing entirely alone: often they may be accompanied (if only lightly) by another bandmember, or the might be joined by a second soloist to perform in duo.

Making this comparison highlights the fact that Davis's rhythm section cuts were not being used as part of the pre-composition process, as was usually the case with earlier lead break, but rather as a device for use during performances, as an improvisational strategy. Yet categorizing the rhythm section cut amongst the musical materials used in the improvisational practices common to jazz would seem just as awkward: clearly it is not a melodic, harmonic or rhythmic device; rather it is a performance gesture that affects the improvisational decisions of the ensemble. Thus I still think it possible to recognize the rhythm section cut as sharing more in common with the tools traditionally associated with the composer, not the improviser. To think about it in this way, however, requires a slight reorientation of our general conceptions of composition and improvisation.

The commentary of Dave Liebman can go some way in helping us here. In describing Davis's role as bandleader during his mid-1970s concert performances, Liebman states: "It was a very disorganised music in a lot of ways...there was no structure, there were no chords, no heads. There was 'you play now.' He'd look at you and you'd play." "96 While Liebman's comments cannot be taken entirely

\footnotetext{
95 Parker's famed break on his 1946 recording of "Night in Tunisia", often thought to have been a product of improvisation was in fact a pre-composed four bar phrase that Parker used repeatedly in each take of the piece that day. See Brian Priestley, Chasin' the Bird: The Life and Legacy of Charlie Parker (New York: Oxford University Press, 2006) 53.

96 Fisher, Miles Davis and David Liebman, 95.
} 
literally - as noted here, there were in fact particular pre-composed elements used in Davis's mid-1970s concert performances, including melodic themes, riffs and drum patterns - what Liebman articulates is that compared to the prescribed nature of more conventional jazz compositions and their performance, Davis's concert performances during this period were considerably less prescribed. However, in making what might seem to be a contradictory comment to his first, Liebman continues: "Judgements of form are [Davis's] biggest quality. Form meaning the whole thing, from how to piece it together to how and when you should play loud to soft, to when to play and not to play. It's how to put things together." ${ }^{97}$ Here Liebman seems to be suggesting that for Davis, as a fusion jazz musician, form was not to be thought of as relating primarily to the act of pre-composition and the creation of musical structure pre-performance. Rather, "how to put things together" was a process that happens in real-time during improvised performance.

For Davis as a bandleader working in a live performance setting, creating musical form in real-time can thus be thought of as being less to do with improvising musical material and more to do with the direction of improvising musicians. In this way his actions as a bandleader can be seen to resemble those of a composer. Using the rhythm section cuts, in particular the solo-cut, Davis could influence what his musicians would play in much the way a composer does through providing precomposed improvisatory vehicles. Yet given that he was doing this during, rather than prior to, performance, his composerly agency was more flexible as it was informed by the particular improvisations of the musicians performing at any given concert. Davis as real-time-composer was able to make decisions related to form through a process of improvisation: his signals of the solo-cuts were themselves improvised and responses to the improvisations of his ensemble. Simply because there is a general lack of pre-composed form in Davis's concerts, does not mean that form and the construction of form does not exist; is it then possible to see the use of the rhythm section cut as the compositional process being drawn into the performance process?

It is this creation of musical form in real-time that I suggest demonstrates a vital creative interrelationship between Davis's studio- and concert-produced fusion jazz. Recall that Macero's post-production tape editing allowed Davis to reorientate composition and improvisation in the recording studio. The fact that the final form of

97 Fisher, Miles Davis and David Liebman, 110. 
a given piece was to be constructed in post-production allowed Davis and his band greater freedom to improvise and interact musically in a more exploratory way. These performances, which were often indistinguishable from rehearsals, became the material from which the final form of the piece was constructed. Similarly, Davis's rhythm section cuts can be seen as formal gestures that, while used to construct form in live performance, allow the musicians a significant degree of freedom to improvise and interact. In this way we can understand Davis's directions of rhythm section cuts on the stage as being informed by Macero's tape editing techniques in the studio. One of the essential qualities of Macero's editing was not the construction of form itself, but the kind of musical creation this editing was able to facilitate. Looking beyond the rhythm section cuts reductively suggests that Davis's use of them facilitated a similar kind of musical practice in concert performance as Macero was able to facilitate in the studio. So while it is tempting to compare the rhythm section cut with the editing heard on "Rated X", if the creative processes that Macero's editing facilitated is considered instead, then we can perhaps come closer to an understanding of a more fundamental interrelationship between the studio and the stage: an interrelationship that underpins Davis's fusion jazz more generally. 


\section{Chapter Four:}

\section{Disorientating Sound as Interactive Accompaniment}

\section{Featured accompaniment in Dark Magus}

As discussed in Chapter Two, Davis's innovative use of the recording studio during the late-1960s and early-1970s involved setting aside the cyclical song forms common to earlier jazz styles and instead developing new methods to compose musical form that foregrounded improvisation and group interaction. Further, as I suggested in Chapter Three, by the mid-1970s, these studio-informed changes in creative process appear to have begun manifesting as rhythm section cuts during Davis's live performances. In this chapter, I delve further into the performance captured on Dark Magus to explore what I see as a second manifestation of the studio-to-stage creative trajectory in Davis's fusion jazz: the featured use of unconventional accompanimental instruments. By paying close attention not just to the musical material produced on each instrument but also to what impact the production of this material has on the lead instrumentalists during passages of improvised solos, it appears that Davis (on electric organ) and percussionist James Mtume (on drum machine) are able to generate a kind of musical disorientation in the performance process that compares to Davis's bandleadership style, evident in his studio recording sessions of the late-1960s and early-1970s. Much like the rhythm section cut, when considered as a manifestation of Davis's studio practices, the featured organ and drum machine accompaniment can be seen as creative approaches that are used to enhance the improvisational process and to influence the activities of the lead improvisers in the ensemble.

Just as when I framed the rhythm section cut as an example of a studio-tostage creative trajectory, when trying to discern a similar creative trajectory in the organ and drum machine accompaniment, careful consideration of creative process is required. First, while again it may initially seem counter-productive, it is necessary to consider the essential differences between the studio and the stage in accounting for creative process. Recall that with the rhythm section cut, it was not until the differences were articulated that a correlation between creative processes could be made apparent. If we are to speculate that Davis wanting to generate in his live performances a similar kind of improvisation-rich music distinctive of his fusion jazz 
studio recordings, we need to consider two of the basic differences between the studio and the stage that would have made this task particularly challenging: the familiarity of prescribed musical material to the ensemble; and the temporal limitations of concert performance. Unlike in Davis's studio recordings, the prescribed musical material on which the improvised concert performances were based was very familiar to many of the musicians in the band. This familiarity contrasts notably with the unfamiliarity of much of the material to most of the musicians who recorded Bitches Brew and On the Corner, many of the fragments of prescribed material used being only a day or two old. Second, as Jeremy Smith has noted, unlike the recording studio, in concert, the band were not able to stop mid performance; once the music was in motion it stayed in motion virtually until the end of the set.

Yet, just because there exist some clear distinctions between the creative acts that occur in the studio and on the stage, it does not necessarily preclude the possibility of a studio-stage interrelationship. This chapter offers an analysis that aims to highlight some of the ways Davis and Mtume's featured accompaniment suggests a transformation of this studio-informed creative process. In my analysis, I focus on the interactive dialogue between soloist and accompanist, as well as the musical interaction between Davis and Mtume. I then consider how this disorientating style of featured accompaniment reflects some of Davis's approaches to disorientating his musicians during the production of his fusion jazz studio albums.

My reference to Davis and Mtume's accompaniment as "featured" is due to the fact that both are used only selectively in Davis's concerts during the mid-1970s. On Dark Magus they heard on only a portion of the eight tracks: Davis's electric organ is heard on "Funk- Prelude", "For Dave-Mr Foster", the reprise of "FunkPrelude", and "Ife"; Mtume's drum machine appears on "Tune in Five"; "FunkPrelude"; and "Ife". The electric organ and drum machine should thus not be thought of as an essential accompaniment instrument within the ensemble in the same way as the drums, bass, or rhythm guitar; instead, they would be better understood as "featured" accompanimental instruments, used relatively sparingly, yet no less effectively. ${ }^{98}$ In the analysis that follows, I focus on Davis's organ accompaniment in "Funk-Prelude" and its reprise, and Davis and Mtume's accompaniment in "Ife".

98 The drum machine also has moments where it features as more of a lead voice. However, it is the role of accompanist that most interests me here in aiming to articulate its use within a studio-tostage creative trajectory. 
The Electric Organ: By way of introduction to my analysis of Davis's organ accompaniment, it is worth considering the particular organ Davis used during the mid 1970s: the Yamaha YC45. Unlike the warmer tone of the Hammond organ more commonly used in earlier jazz styles, the YC45 has a bright, metallic timbral quality and has the potential to produce incredibly harsh and abrasive tones. What is more, by using several effects pedals, including overdrive and Wah-Wah, Davis could further enhance the tonal extremities of the organ. ${ }^{99}$ Davis also used a volume pedalan expression pedal commonly paired with electric organs - to modulate the instrument's volume.

In "Funk- Prelude" Davis enters on organ at 5:03, shortly into Cosey's guitar solo, playing a dense chromatic cluster of notes. Saturated in overdrive, the sounds produced by Davis can be barely recognized as those of an electric organ. This dissonance, both harmonic and timbral, seems to have an immediate effect on Cosey in his development of improvised melodic ideas: having previously been playing simple, blues-based melodic phrases, the guitarist's ideas become increasingly complex soon after Davis's accompaniment begins, not just rhythmically and melodically but, given Cosey's increased use of overdrive and Wah pedal, also timbrally. As Cosey gradually returns to playing more melodically-discernable phrases, he climbs to a peak in register at 5:16. Davis responds to this increase in intensity by playing another chromatic cluster, this time higher in the organ's register. To increase this chords' timbral dissonance, Davis uses the Wah pedal, sweeping the organ's frequencies from high to low, at first slowly and then more rapidly. The fluency of improvised interaction between guitarist and organist in this passage indicates Cosey's ease at responding to Davis's disruptive accompaniment.

Yet, even as one of the strongest soloists in Davis's band, Cosey soon appears to be challenged by the bandleader's accompaniment. Following a particularly dissonant chord, played by Davis 5:35 and sustained until 5:41, the guitarists improvised phrases seem to briefly lack the conviction so immediately apparent in the rest of his playing on Dark Magus. After this moment of unsettledness, Cosey

99 Davis first started using the Wah-Wah pedal with his trumpet in the early 1970 s, some commentators suggesting it was his attempt to adopt ideas from one of the Wah's chief exponents, Jimi Hendrix. By the mid-1970s virtually all Davis's band members were using the Wah, including guitarists Cosey and Lucas, bassist Henderson, and Mtume on drum machine. The most common Wah pedal being produced at the time was the Dunlop CryBaby. 
struggles to regain momentum: he continues to play sparse, melodic, blues phrases, which although offering some contrast to his previous dense melodic phrases, do not develop in any significant way. Perhaps noticing this growing stagnation in Cosey's solo, Davis drops out, seemingly to give Cosey some more space to develop his ideas; however, Cosey does not alter his melodic approach in any significant way. Apparently not content with Cosey's ambling solo, Davis soon re-enters — and with noticeable aggression. At 6:19 Davis plays an incredibly startling chord: using the Wah pedal he boosts the high frequencies of his organ so drastically that the pitches become utterly indistinguishable; slowly adjusting the Wah, he creates the effect of a cascade of high-pitched frequencies with an intensely bright sonic texture. Cosey responds virtually immediately, intensifying his improvised lines, shifting between blues phrases — heavily affected by his own Wah pedal—and sheets of sound. During the passage that follows, the interaction between Cosey and Davis is particularly strong, with the guitarist closely matching Davis's changes in intensity of pitch, tone, and rhythm, and the ebb and flow of their phrases weaving together in an masterfully improvised synchronicity.

Davis features again as an accompanist in the reprise of "Funk-Prelude." During the piece's opening moments, he uses the organ to create significant harmonic contrast. With the tonal centre being established by Henderson who plays a bass riff built around the B-flat minor pentatonic scale, Davis plays several sustained chords that diverge from this tonality. Perhaps the most striking passage is at $1: 34$, where Davis plays a B-minor chord, up a semitone from the piece's tonal centre. The soloist during this passage — guitarist, Reggie Lucas—responds by modulating up a semitone himself. Henderson's responds to this shift in tonality by simply by dropping out entirely! However, the harmonic space Henderson's absence provides allows Lucas and Davis to briefly divert from the central groove of the piece to create a short moment of harmonic tension. At 1:53, this tension is released as Davis and Lucas return to the B-flat minor, at which point Henderson re-enters.

At around 2:30, guitarist Dominique Gaumont begins his solo. During his organ accompaniment of Gaumont, Davis's approach becomes considerably more abrasive. Leaving Gaumont to begin his solo with accompaniment from the band's rhythm section only, Davis soon re-enters at 2:52, hitting an incredibly dissonant cluster of notes in the organ's higher register while modulating its tone with the Wah. Initially, Gaumont seems to be thrown off-balance; however, he quickly gathers 
himself, responding by becoming more dissonant and abrasive in his own solo, and continuing in this manner until Davis drops out at 3:09. Davis repeats this accompanimental approach at 5:58: as Davis shifts through a series of dissonant cluster chords that conflict strongly with the piece's tonal centre, Gaumont responds by increasing the overall dissonance of his playing, moving into the upper register of his guitar, obscuring particular notes being played with the heavy use of Wah pedal. Here Gaumont responds to Davis's accompaniment quickly and with conviction, pushing beyond safer melodic ideas and familiar phrases.

Perhaps the most striking passage of Davis's accompaniment in the reprise of "Funk-Prelude" occurs between 6:34 to 6:57. During this passage, Davis seems to take up a rhythmic idea first heard being played by Azar Lawrence in the background of Gaumont's solo between 4:42 to 4:51—almost two minutes prior. Davis develops the idea, experimenting with some contrasting and quite disconcerting rhythmic feels. Here, by destabilising the consistency of the rhythmic feel set up by the rhythm section, Davis is able to generate a kind of rhythmically disorientating sound. Whereas Gaumont's response to Davis's accompaniment had, up until this point, been well-controlled, following Davis's disruption in the groove, the guitarist's flow of melodic ideas is cut short; he then struggles to lock back in with the rhythms Davis is playing. And, as if the disorientating sound of this rhythmically-disruptive passage was not enough, Davis follows it with an extremely dissonant and abrasive sustained chord at 6:58. Rather than floundering, however, Gaumont miraculously picks himself up and responds with considerable conviction, building to another high point in his solo. Shortly thereafter at 7:31 Davis directs the first rhythm section cut that Gaumont is subjected to in the piece (as discussed in Chapter Three).

In certain ways Davis's organ accompaniment in "Funk-Prelude" and its reprise clearly does not align with the kind of chord-based accompaniment (whether piano or guitar) common to earlier jazz styles. The harmonic and rhythmic content of his organ-work is often times highly ambiguous: rhythmically, he will often either play sustained chords that fail to impart discernable rhythmic support, or create strong rhythmic material that clashes with the underlying groove of the piece; harmonically, the tonality of the chords played are often obscured by overdrive and tone-modulation (through the use of the Wah pedal) and clashing with the piece's tonal centre. The accompanimental material generated by Davis can thus be understood as musically disorientating: rather than reinforcing a given piece's core musical structure in 
support of the soloist, Davis seems to want to obscure this structure. In doing so, however, he is able to push the soloist beyond what they had been previously playing, to go for something new and unexpected instead.

The Drum Machine: The presence of a drum machine in Davis's band would strike most observers as perplexing. Beyond being an instrument that is generally thought of as out of place in a jazz-orientated performance setting, Mtume's use of the drum machine does not align with contemporary notions of how such an instrument is intended to function. Indeed, what is most striking about Mtume's uses the drum machine is his radical "misuse" of it. ${ }^{100}$ By overlapping the drum machine's various preset grooves and manipulating its playback tempo, volume and tone, the sound being produced by the instrument is less like that of a virtual drum set and more like an indistinguishable blur of electronically-generated sound. In Mtume's words: "instead of using it to create rhythm, I wanted to see whether I could use it to create texture." ${ }^{101}$ Below, I focus my analytical attention on the drum machine's use in "Ife" as Mtume accompanies the solos of Cosey and Liebman. What is also notable about "Ife" is that Mtume and Davis often appear to work in dialogue as featured accompanists by responding to each other's changes in timbre, volume and rhythmic density.

"Ife" opens with the solo of Cosey on guitar. The rhythm section generate a slow and steady groove: Foster plays a straight rock beat, punctuated with the occasional syncopated fill; Henderson shifts between a slightly frantic chromatic motif $(\mathrm{B} b-\mathrm{A}-\mathrm{A} b-\mathrm{A}-\mathrm{B}$ b ) and a simple riff $(\mathrm{A} b-\mathrm{A} b-\mathrm{B} b-\mathrm{B} b)$, leaving quite a bit of space between the reiteration of each; Lucas can be heard experimenting with some different idea that compare to what Henderson is playing, while also providing breathing space between each phrase. Cosey's improvisational approach is similar to "Tune in Five" as he shifts between short blues-inflected phrases and sheets of sound, all the while manipulating the tone of his guitar with Wah pedal. Davis and Mtume both enter shortly thereafter at 00:27, quickly creating a sense of tension as they both increase in volume through until 00:35. Cosey responds by increasing his

\footnotetext{
100 See Appendix.

101 Tingen, Miles Beyond, 165.
} 
phrases in rhythmic density. ${ }^{102}$ Then, from 00:35 through 00:49, there is a fluctuation of tension generated by the two featured accompanists: as Davis shifts between consonant and dissonant chords, Mtume reduces his tempo in response to Davis's more dissonant chords while increasing his tempo in response to those chords that are more consonant. During this passage, Cosey is more subdued, keeping low in register and manipulating his guitar's tone, cutting the higher frequencies with his Wah-pedal, leaving space for Davis and Mtume to move to the foreground. At around 00:49, Mtume changes the groove of his drum machine, which produces a brighter tone. Davis responds by shifting to a more consonant chord, which he sustains for several seconds. Cosey remains low in dynamics, playing long sustained notes that he blends with feedback, while continuing to use his Wah-pedal to supress the guitar's high frequencies. Through the interactive accompaniment of Davis and Mtume, and Cosey's sympathetic soloing, there is a considerable amount of tension generated in the opening moments of "Ife".

At 1:04, Cosey breaks this subdued tension with a vibrant blues-inflected phrase, which Davis soon responds to, brightening the tone of his organ with the Wah-pedal and shifting to shorter and more rhythmically active chords. Mtume sustains the same groove for almost the entire passage, increasing slightly in volume and only changing to a new groove around 1:21, at which point he drops back in the mix by cutting the high frequencies and darkening the drum machine's tone. Cosey gradually builds his solo in rhythmic density and register, still shifting between blues phrases and sheets of sound, the latter corresponding to the rhythmic density and metric ambiguity of Mtume's drum machine accompaniment. Around 1:30, rather than releasing the tension created in the previous passages and progressing into more stable material, Davis drops out altogether, delaying the release of the tension by leaving only the bare bones of the rhythm section to play; Mtume responds by becoming far more active, shifting quickly between the various preset grooves on the

\footnotetext{
${ }^{102}$ Greg Tate, suggesting that Cosey used his guitar in ways that departed from a conventional lead soloist, comments: "Cosey's guitar simultaneously functions like a second set of congas to Mtume's, a second rush of cymbals to Al Foster's, a second steel drum simulacrum to Miles' Gnostic organ, a second rhythm guitar to Lucas', and as one of the three solo voices." Tate, 'The Electric Miles', 23. My interpretation is that, rather than functioning as an accompanimental instrument in the way Tate gestures, Cosey's guitar still operates in the lead guitar mode; the similarities noted by Tate are more a indication of the guitarist's astute awareness of the particularity of the material being produced by the other musicians in the band and a sign of his ability to develop musical interplay that extends beyond the conventional materials of Western music.
} 
drum machine. During this passage Cosey moves from guitar to percussion, playing hand-held bells, which share with the drum machine's dense rhythmically ambiguity.

At 1:48, Davis (now on trumpet) and Liebman finally enter with the theme of "Ife," shifting up a tone from B-flat minor to the key of C minor. As the theme unfolds, Foster's drums gradually dissolve, and Mtume's drum machine creeps into the foreground again, building a sense of suspense and setting up Liebman's solo with a heightened feeling of tension. In accompanying Liebman, Mtume is far more active than in the previous section, shifting between different preset-grooves and frequently fluctuating in volume and tempo. However, Liebman does not seem to be unsettled by the rhythmic ambiguity of Mtume's accompaniment; indeed, he seems to relish it, playing one of his most strongest solos in the whole concert.

Again, as during Cosey's solo, Mtume and Davis accompany the lead instrumentalist in tandem, although in this instance Davis holds off until halfway into Liebman's solo before entering. During this first section of Liebman's solo, rather than engaging in a direct call and response with the Mtume, the saxophonist uses the drum machine accompaniment more as a timbral and rhythmic contrast to his own playing. Liebman opens his solo remaining relatively restrained in his improvised phrases, only playing the occasional explosive phrase (for instance at 2:34, and between 2:39 and 2:54). Mtume's constant shifting amongst the preset grooves of his drum machine creates further tension; and as Mtume keeps dropping out and reentering, the unsettling feeling is greatly enhanced. At 3:05 as Liebman reaches a peak in his solo, Davis returns on organ. Davis and Mtume begin their second passage of dual accompaniment, creating an incredibly powerful foundation for Liebman to extend the peak of his solo and then gradually drop back to a lower dynamic. As Davis sustains long, dissonant clusters of notes, Mtume, rather than sustaining long stretches of the same groove, drops in and out, shuffling between different grooves. By 4:20, as Liebman's solo draws to an end, and with the energy gradually decreasing, for the first and only time in the concert, Mtume reduces the tempo of his drum machine to the point where the preset-groove being played back can actually be recognized as a groove! This oddity makes it all the more effective as a conclusive gesture, clearly framing the end of Liebman's solo. ${ }^{103}$

\footnotetext{
${ }^{103}$ Mtume commented: "Our concerts began like a balloon that was incredibly compressed...After that it was a matter of gradually letting the air out." Tingen, Miles Beyond, 164. The reduction of the drum machine's tempo to a recognizable groove seems to capture this feeling of a balloon nearing
} 
Mtume's use of the drum machine as an accompanimental instrument clearly departs from the kind of rhythmic accompaniment common to earlier jazz styles: rather than offering the rhythmic stability as the guitar, bass, drums and other percussion instruments might do, he uses the drum machine to generate a strong sense of rhythmic ambiguity, which has the potential to unsettle the soloist being accompanied. Much like Davis in his approach to accompanying the soloist during "Funk-Prelude" and its reprise, Mtume's drum machine accompaniment can be understood as effecting a kind of musical disorientation for the soloist. By clashing with the foundational groove established by Foster, Henderson and Lucas, the drum machine accompaniment has the potential to undermine a sense of rhythm continuity, putting the steadiness of the groove is at risk of being compromised. Yet at the same time, this kind of accompaniment is highly effective at promoting exciting solo improvisation.

\section{Disorientating sound and real-time composition}

It should be noted here that these disorientating accompanimental approaches do bear some similarities both to Davis's earlier music and to the work of musicians associated with the jazz avant garde of in the two decades leading up to fusion jazz's rise. During the 1960s, as Davis was beginning to move away from prescribed cyclical form his expectations for the accompanists in his band was also changing. Herbie Hancock recalls that during the mid-1960s, Davis's loosening of musical form required the pianist adjust his approach to supporting the soloist: "I had to find sounds (not so much chords)...to provoke you [the soloist] and stretch yourself." ${ }^{104}$ Similarly Cecil Taylor's accompanimental approach, even as far back as the late-1950s, seemed intended to unsettle the lead soloist. Ekkehard Jost sees Taylor's rhythmic manipulation - his disruption of a performance's underlying groove - as an effort to "creat $[\mathrm{e}]$ a kind of energetic tension... More often than not, this gave a peculiar 'cramp' to the rhythm." ${ }^{105}$ Drummers of the jazz avant garde, too, were also moving away from strict rhythmic support, and towards an increasingly foregrounded

\footnotetext{
the end of its deflation.

${ }^{104}$ Quoted in Szwed, So What, 265.

105 Jost, Free Jazz, 70.
} 
dialogue with the soloist. John Litweiler describes Sunny Murray and Milford Graves as "liberating the drums from the time keeping function." "106 It seems unlikely, however, that these new approaches to accompaniment were informed by a change in creative process forged in the recording studio - and certainly not to the degree that I have aimed to highlight in Davis's fusion jazz. Perhaps if jazz historians were to explore in greater depth the potential for a similar studio-to-stage creative trajectory in Davis's earlier work and the work of musicians associated with the jazz avant garde of the 1960s it may be possible to discern similar, yet undoubtedly unique, studio-stage interrelationships.

Having highlighted above the accompanimental approaches taken by Davis and Mtume during concert performance, I feel these approaches can be compare in an interesting way to some of Davis's disorientating approaches to bandleadership in the production of his studio recordings during the late-1960s and early-1970s. This comparison seems especially true when considering how the pre-composed material being used was becoming less essential to the total composition-improvisation process during this period. Without the kind of prescribed formal material common to earlier jazz styles, Davis and his band were without what had once been an essential ingredient for generating interesting and coherent improvised performances: cyclical form was the foundation on which melodies were improvised, accompaniment generated and interaction between these two processes facilitated; something needed to replace cyclical form were there to be some kind of structure to inform group improvisation. In the studio and on the stage, Davis and his bandmembers can thus be understood to depend in some way upon musical disorientation as a means to provoke exciting improvised performance. By providing only the most basic pre-composed material for improvisation, yet complicating this material during the improvisational process through using musically disorientating strategies, Davis, as a bandleader, could enhance spontaneous musical production. In the studio these strategies included fragmenting the record production process, overlapping rehearsal and recording, and restricting access to musical materials (recall Liebman's first studio session with Davis, for instance). On the concert stage, by featuring accompanimental instruments and techniques capable of disorientated the soloists, Davis could generate a similar kind of spontaneity in the musical creation process.

${ }^{106}$ Litweiler, The Freedom Principal, 137. 


\section{Conclusion}

To conclude this thesis, I think it is useful to consider the studio-stage interrelationship of Davis's fusion jazz in light of the theoretical concept of liveness. One of the first authors to develop a contemporary theory of liveness was performance-studies scholar, Philip Auslander. ${ }^{107}$ Auslander sees twentieth and twenty-first century live performance as inherently shaped by performers' and audiences' engagement with technologies of mediation. Accordingly, "live" performance is becoming increasingly similar to its mediatized equivalent; it is created less in opposition to, but rather, in light of, mediatized performance. The kind of studio-to-stage creative trajectory I have aimed to articulate in discussing Davis's fusion jazz could on one level stand as an example of the kind of interrelationship between the mediatized and live performance that Philip Auslander has theorized. The creative trajectory of Davis's fusion jazz would exemplify a live performance practice that has been shaped by an element of mediating technology, thus demonstrating a form of mediatized live performance. Yet when compared to Auslander's own examples of mediatization in live performance, which he often treats as problematic, this kind of creative trajectory would surely be seen less as a negative example of mediatization and more as a process that would extend, possibly even liberate, creativity within a live improvised musical performance setting. As I have aimed to highlight in my analyses of Dark Magus, mediating technologies, rather than delimiting the kinds of egalitarian music making processes so distinctive of jazz-in particular live jazz performance - actually aided Davis in developing new approaches to the creative challenges of composition and improvisation.

Accordingly, if understood as an example of mediatization, the studio-to-stage creative trajectory outlined in this thesis would stand as an alternative reading to Auslander's pessimistic view of mediatized live performance. Much in the way that Paul Sanden has offered counter-examples to Auslander, I would like to posit Davis's

\footnotetext{
107 Philip Auslander, Liveness: Performance in a Mediatized Culture. (New York : Routledge, 1999). On the effect of mediating technologies on the production and reception of musical performance see Timothy Day, A Century of Recorded Music: Listening to Musical History (New Haven, CT: Yale University Press, 2000). Robert Philips, Performing Music in the Age of Recording, (New Haven, CN: Yale University Press, 2004); and Georgina Born, “On Musical Mediation: Ontology, Technology and Creativity", Twentieth-Century Music, 2/1 (2005), 7-36.
} 
negotiation of the mediating technologies of his time as an activity rich with human agency. ${ }^{108}$ It seems clear to me that Davis, as a fusion jazz musician was not dominated by mediating technology. Rather, I see Davis's development of creative processes from the recording studio for use on the concert stage as a willing attempt to subsume recording technology into his acts of musical creation, taking what was traditionally seen as an impediment to creativity and flipping it on its head, using to his advantage something that had often previously been thought of as a creative limitation for jazz musicians. In this way, I see Davis's engagement with technology as a successful negotiation of the particular technological structures of his time. If we accept that an actor's efforts to achieve a sense of freedom-whether aesthetic, social or economic - is going to be affected, to a greater or lesser extent, by the structures and institutions particular to his or her historical moment, then we can surmise that the attainment of this sense of freedom is more likely to occur if that actor is to some degree conscious of those structures and institutions. To me, the fusion jazz of Miles Davis, when understood in terms of a studio-to-stage creative trajectory, demonstrates the kind of sophisticated technological reflexivity required to make some kind of autonomous artistic statement within a world inherently shaped by the structuring forces of technology.

With this thesis, in making the case for a studio-to-stage creative trajectory in Davis's fusion jazz, I hope to have sparked further interest in similar studio-stage interrelationships in the work of other fusion jazz musicians. Given, on the one hand, the sheer diversity of music associated with fusion jazz, and on the other hand, the broader claim that fusion jazz is a distinctly phonographic style of jazz, it is quite possible that there exists an wide array of different studio-to-stage creative trajectories within the style. While I have focused on the way Davis's use of tape-editing became a central part of his creative process in the studio and how it went on to inform his approach to making music in a live setting, I do not mean to suggest that this kind of technology or record production technique could be the only way in which fusion jazz musicians used recording technology. There were in fact a range of technologies and techniques being used by other fusion jazz musicians in the studio, including multitrack recording, audio effects units, and analog synthesizers. Accordingly, we might ask: how could the use of multitrack recording technology in the studio have

${ }^{108}$ Paul Sanden, Liveness in Modern Music (New York: Routledge, 2013). 
informed fusion jazz musicians' creative decisions in live performance settings? Or how may the use of audio effects units in the studio have influenced musicians' approaches to sonic exploration on stage? And how did the use of synthesizers housed in recording studios inform the use of portable electronic keyboards and synthesizers in concert? These are just some of the many questions that remain to be answered regarding a studio-stage interrelationship in fusion jazz.

And, while I have implied that Davis's studio-to-stage creative trajectory can be treated as a stylistic signifier of fusion jazz, it has not been my intention to proscribe the articulation of other kinds of studio-stage interrelationships in earlier (or later) jazz styles. Indeed, if concert performance and recorded performance in Davis's fusion jazz were not necessarily two parallel practices, but rather overlapping creative activities, is it not possible that there exist other kinds of interrelationships between the studio and the stage in jazz? Raising such a speculation may seem counterproductive to my claims; however, it has been my intent only to articulate a kind of studio-stage interrelationship particular to Davis's fusion jazz, and as a loose representative of fusion jazz more generally.

Personally, having conducted this study, my feeling now more than ever is that efforts to generate greater knowledge about the technologically-mediated nature of jazz could be some of the most productive work for jazz scholars to be doing at this point in time. A jazz historiography that includes a critical perspective on recordings need not be seen as a privileging of the recording, nor need it be seen as a claim that jazz musicians' creative processes, or any degree of their creative agency, are ultimately circumscribed by technology. Rather, given that recordings are one of the primary mediums a jazz historian works with, it is essential that he or she have a sound knowledge of the distinctive features and peculiarities of that particular medium. If scholars involved in the professional study of Western art music are expected to hold critical perspectives about the mediums of their source material, then scholars of jazz, too, should aim to include the same kind of rigorous understanding of their objects of study in their own methodological toolkit. Indeed, as Jed Rusula has provocatively argued, one of the greatest risks a jazz historian can fall pray to when working with recordings is to losing sight of the potent temporal and cultural 
otherness that recordings represent. ${ }^{109}$ Now more than ever in the digital age, "equal" access to "unequal" recordings means that contemporary audiences are at significant risk of anachronistic listening. For instance, in listening back to back on an iPod to the Original Dixieland Jazz Band's "Livery Stable Blues" and Miles Davis's "Rated X", it is all too easy for the unique material conditions and lived experiences of every agent involved in each recording's creation to be obscured. Thus, even as sonically visceral historical artefacts, recordings have the potential to flatten and distort the past.

As a critical and analytical perspective, then, exploring studio-stage interrelationships in other jazz styles could greatly enrich the historical study of jazz. If such studies aim to investigate both the contingencies and continuities of the historical and aesthetic conditions that jazz musicians find themselves in, then critical attention to recordings, and their implication in creative process, could prove particularly productive. Considering the unique ways in which different musicians approached the tasks of listening to, learning from, and producing recordings, and how these activities overlapped and interacted with practices and conceptions of composition and improvisation can surely reveal the diversity in creative approaches between the likes of Louis Armstrong, Charlie Parker, Miles Davis and John Coltrane; it can reveal the plurality of jazz practice, and the distinctiveness of each individual. Yet it could also highlight some of the essential similarities between such musicians: jazz's nature as a soloist's music, and as a music that relies on improvisation and group interaction. Indeed, for any listener of jazz recordings, an understanding of the relationship between the artefact they are engaging with and the creative processes that produced that artefact could surely be valuable in aiding the interpretive process, and make their engagement with the past that much more meaningful.

\footnotetext{
${ }^{109}$ Jed Rasula, 'The Memory of Meaning: The Seductive Menace of Records in Jazz History', in Jazz Among the Discourses, ed. Krin Gabbard, Durham: Duke University Press, 1995, 134-162.
} 


\section{Appendix:}

\section{The Drum Machine From Henry Cowell to James Mtume}

One of the most distinctive features of Davis's concert performances from 1973 through to 1975 was the use of a drum machine by percussionist James Mtume. To the best of my knowledge Davis's band was the only fusion jazz band to use the drum machine during the mid-1970s; it is also highly likely that Davis was the first major figure in jazz history to use the drum machine in a jazz performance setting. Given this distinctiveness it is very surprising that much of the literature to address Davis's work from this period fails to mention the drum machine's presence. ${ }^{110}$

For many audiences today the conception of the drum machine is most often associated music of the digital age: disco, hip hop, techno and a myriad of other electronic music genres to emerge in the late 20th and early 21 st century. However, the technology so distinctive of these musics had its origins in what might be unexpected places: the labs of electronic music composers and the small venues of everyday working musicians.

The first known drum machine is Leon Theremin's Rhythmicon, an instrument he was commissioned to invent during the 1930s by composer Henry Cowell. The composer's desire for the machine was initially fuelled by his frustration with the inability of musicians to perform the complex polyrhythmic material he was composing at the time. Cowell felt that "such a rhythmic instrument was a necessity to further rhythmic development, which [had] reached a limit more or less, in performance by hand, and needed the application of mechanical aid." 111 What made the Rhythmicon different from most instruments before it was its ability to produce sounds that did not directly replicate to the physical movements of its controller: to press a single key created a series of rhythmic subdivisions; the output of musical material created by the machine differed from the movement of the controller's body.

\footnotetext{
${ }^{110}$ While Stuart Nicholson and Davis biographers Ian Carr, Jack Chambers, and John Szwed all pay close attention to the music Davis produced during the late-1960s and 1970s, not one of them mentions the use of the drum machine in Davis's band during this period. Nicholson, Jazz-Rock; Ian Carr, Miles Davis; Jack Chambers, Milestones: The Music and Times of Miles Davis (New York: Da Capo Press, 1998); John Szwed, So What.

111 Cited in Margaret Schedel, 'Anticipating Interactivity: Henry Cowell and the Rhythmicon', Organized Sound, 7/3 (247-254), 249.
} 
As Margret Schedel suggests, the Rhythmicon was the first instance of an instrument "to distance gesture from sound," a development in music technology that Cowell embraced. ${ }^{112}$

Following the preliminary excitement about the Rhythmicon's potential the instrument failed to gain popularity, with neither Theremin nor Cowell attempted to produce their instrument on mass scale. Schedel speculates that there were only three Rhythmicon's constructed. ${ }^{113}$ It was to be several decades before the first commercially successful drum machine was created: the Wurlitzer SideMan, released in 1960. Like the Rhythmicon, the Sideman was used to replace the human musician, albeit for a purpose that seemed to be guided more by economic concerns than aesthetic interests. As Sarah Angliss comments:

In naming it the SideMan, Wurlitzer was pitching their musical instrument as an economic proposition. And in pointing out the convenience of a "rhythm section at your side," they were glossing over its obvious deficiency - the loss of a human drummer who can interact with other live musicians. ${ }^{114}$

Angliss sees Wurlitzer as being somewhat cynical in their marketing of the SideMan: it was apparent to them that the machine was unable to completely fulfil the role of a human drummer; nevertheless, for their intended market, the economic benefits could potentially override the loss of human agency.

By the late 1960s and in the wake of the SideMan's popularity, the Musician's Union in the United Kingdom was calling for its members to boycott the growing number of drum machines becoming available on the music technology market. Notably, the potential that the jobs of real live musicians would be lost to machines, mirrored the fears that were being felt among many of the working class of the Western world during the 1960s. As Angliss writes: “Arguably, [drummers] were in the same economic jeopardy as any other skilled labourer in competition with a machine, such as a metalworker about to be ousted by a new automatic lathe."115

\footnotetext{
112 Schedel, 'Anticipating Interactivity', 248.

${ }^{113}$ Ibid., 258. Other early drum machines included the Chamberlin Rhythmate - a predecessor to the more popular Mellotron - first going on sale in 1948, and composer and music technologist Raymond Scott's Circle Machine (1959). See Sarah Angliss, 'Mimics, Menaces, or New Musical Horizons? Musicians' Attitudes Toward the First Commercial Drum Machine and Samplers', in Material Culture and Electronic Sound, ed. Frode Weium and Tim Boon (Washington D.C.: Smithsonian Institution Scholarly Press, 2013), 95-130.

114 Angliss, 'Mimics, Menaces, or New Musical Horizons?', 99.

115 Ibid., 96.
} 
Davis's interest in the drum machine may have been motivated by his love of Sly Stone's music. Stone's hit single "Family Affair", from his 1971 record, There's a Riot Goin' On is one of the first instances of a drum machine being used by a wellknown popular musician. He also followed up Riot in 1973 with Fresh, another album which featured the drum machine, and an album with which Miles Davis became obsessed. $^{116}$

Mtume's use of the drum machine in Davis's band is likely to have begun during the first half of 1973. One of the earliest instances of its use is captured on a recording made of a concert that took place on April 12th 1973, but it is probable that Mtume was using it throughout the same tour, which begun in March of that year. ${ }^{117}$ It is not immediately clear, however, which brand and model of drum machine Mtume was using. Paul Tingen quotes Mtume saying that, prior to the band's departure for the Japanese tour, Yamaha, the sponsor for the tour "gave Miles their first drum machine. Miles handed it to me and said 'see what you can do with it.",118 But in looking for other evidence to support Mtume's claim, it would seem his recollection of these events are slightly amiss. First, Yamaha did not commercially release a drum machine until 1982: the Yamaha MR10, their first and only analogue drum machine. ${ }^{119}$ What is more, documentary evidence - in particular, film footage of Miles's band playing during 1973 - depicts Mtume playing what appears to be another popular model of drum machine at the time: the Korg Mini Pops 3, released in the United States branded as the Vintage Univox SR-55. ${ }^{120}$ Throughout this thesis I have assumed Mtume was in fact using a Vintage Univox SR-55 during much of his

\footnotetext{
${ }^{116}$ See Liebman's commentary in Fisher, Miles Davis, 111.

117 See Peter Losin, 'Miles Davis Session Details: April 12, 1973', < http://www.plosin.com/MilesAhead/Sessions.aspx?s=730412>, 30 March 2015.

118 Paul Tingen, Miles Beyond: The Electric Explorations of Miles Davis, 1967-1991 (New York : Billboard Books, 2001), 163.

119 'MR-10 Personal Studio System Info Page', < http://www.dubsounds.com/mr-10.htm>, 30 April 2015.

120 'Miles Davis Electric 73 Montreux Part 1', <https://www.youtube.com/watch?v=E4PYJhh8ooo \&index $=1 \&$ list=PL541693D663C56290\&spfreload=10>, 30 March 2015; 'Miles Davis Electric 73 Montreux Part 2', <https://www.youtube.com/watch?v=-Fi_DeP55mQ\&list=PL541693D66 3C56290\&spfreload=10>, 30 March 2015; 'Miles Davis Live at Montreaux1973 Calypso Frelimo Unreleased Part', <https://www.youtube.com/watch?v=rfRlZCzqlIg\&spfreload=10>, 30 March 2015.
} 
time with the Davis band, including during the concert heard on Dark Magus.

Like most drum machines produced during the 1960s and 1970s, the SR-55 was manufactured with a set number of programmed rhythmic drum patterns (or grooves) that could be selected and played back. The selection of preset grooves consisted of rhythms from a range of musical styles: foxtrot, swing, rock, ballad, western, bossanova, tango, habanera, rumba, beguine, mambo, cha cha, baton, and waltz. ${ }^{121}$ Each groove is constructed from a combination of kick drum, snare, tom, hihat, rim shot, clave and cow bell sounds. These electronically generated sounds, while barely resembling the sonic qualities of an acoustic drum kit or percussion instruments, are at least able to approximate their generalised pitches and timbres, and are sufficient for creating the illusion of a drum groove.

One of the features of the SR-55, like many drum machines from the same period, is the ability to combine different combinations of drum grooves. For instance a basic $4 / 4$ rock groove could be doubled up with a bossanova drum pattern, thus creating a denser rhythmic texture. At the extreme end of this kind of groove combination - all drum grooves played at once - the sound is one of cacophony: there is no rhythmically distinguishable groove, only a repetition of all the machine's different instrument sounds played at the highest rhythmic subdivision they have been programmed to potentially sound; the different grooves being played back become indistinguishable. The SR-55 is also able to playback these grooves at extremely fast tempos. Accordingly, a straightforward 4/4 rock drum beat, clearly distinguishable at a medium tempo such as 150 B.P.M. becomes unrecognizable when that tempo is tripled (many of the SR-55's grooves heard on Dark Magus are played back by at over 400 B.P.M). Beyond the ability to combine different grooves and adjust the tempos of these grooves, the parameters of the SR-55 are limited to volume and tone.

${ }^{121}$ For a demonstration of the Univox's basic sounds and parameters see 'Univox SR-55 Vintage Analogue Drum Machine Demo', <https://www.youtube.com/watch?v=HXPAb Fr02bk\&spfreload=10>, 30 March 2015. 


\section{Sources}

\section{Bibliography}

Ake, David. 'Re-Masculating Jazz: Ornette Coleman, "Lonely Women" and the New York Jazz Scene in the Late 1950s.' American Music 16/1 (1998), 25-44.

Angliss, Sarah. 'Mimics, Menaces, or New Musical Horizons? Musicians' Attitudes Toward the First Commercial Drum Machine and Samplers.' In Material Culture and Electronic Sound, ed. Frode Weium and Tim Boon. Washington D.C.: Smithsonian Institution Scholarly Press, 2013, 95-130.

Armstrong, Isobel. The Radical Aesthetic. Oxford: Blackwell, 2000.

Auslander, Philip. Liveness: Performance in a Mediatized Culture. New York: Routledge, 1999.

Baraka, Amiri. 'Where's the Music Going and Why?' In The Music: Reflections on Jazz and Blues. New York: William Morrow, 1987. 117-180.

Bergerot, Franck. We Want Miles: Miles Davis. New York: Skira Rizzoli, 2010.

Berliner, Paul. Thinking in Jazz. Chicago: University of Chicago Press, 1994.

Bijker, Wiebe, Thomas P. Huges, and Trevor Pinch, eds. The Social Construction of Technological Systems: New Directions in the Sociology and History of Technology. Cambridge, MA: MIT Press, 1987.

Bimber, Bruce. 'Karl Marx, and the Three Faces of Technological Determinism.' Social Studies of Science 20/1 (1990), 333-351.

Born, Georgina. 'On Musical Mediation: Ontology, Technology and Creativity.' Twentieth-Century Music 2/1 (2005), 7-36.

Brown, Jake. Behind the Boards: The Making of Rock 'n' Roll's Greatest Albums Revealed. Milwaukee, WI: Hal Leonard Books, 2012.

Brownell, John. “Analytical Models of Jazz Improvisation.” Jazz Research Journal 26/1 (1994), 9-27.

Carr, Ian. Miles Davis: The Definitive Biography. London: HarperCollins, 1998. 
Chambers, Jack. Milestones: The Music and Times of Miles Davis. New York: Da Capo Press, 1998.

Chanan, Michael. Repeated Takes: A Short History of Recording and its Effects on Music. London: Verso, 1995.

Cohen, Harvey. Duke Ellington's America. Chicago: University of Chicago Press, 2010.

Collier, James Lincoln. The Making of Jazz: A Comprehensive History. Boston, MA: Houghton Mifflin, 1978.

Cook, Richard. It's About That Time: Miles Davis On and Off the Record. London: Atlantic, 2005.

Coryell, Julie \& Laura Friedman. Jazz-Rock Fusion, the People, the Music. New York: Dell Publishing Company, 1978.

Crouch, Stanley. 'Play the Right Thing.' The New Republic (February 12), 30-37.

Danielsen, Anne. Presence and Pleasure: The Funk Grooves of James Brown and Parliament. Middletown, CT: Wesleyan University Press, 2006.

Day, Timothy. A Century of Recorded Music: Listening to Musical History. New Haven, CT: Yale University Press, 2000.

Demers, Joanna. 'Materialism, Ontology, and Experimental Music Aesthetics.' In Tomorrow is the Question: New Directions in Experimental Music Studies, ed. Benjamin Piekut, (Ann Arbor, MI: University of Michigan Press, 2014), 267.

DeVeaux, Scott. 'This is What I Do.' In Art from Start to Finish: Jazz, Painting, Writing, and Other Improvisations, ed. Howard S. Becker et al. Chicago: University of Chicago Press, 2006, 118-125.

Eisenberg, Evan. The Recording Angel. New Haven, CT: Yale University Press, 2005.

Ellison, Ralph. 'The Charlie Christian Story.' In Shadow and Act. New York: Vintage Books, 1972 [1958], 233-240.

Fellezs, Kevin. Birds of Fire: Jazz, Rock, Funk, and the Creation of Fusion. Durham: Duke University Press, 2011. 
Finnegan, Ruth. Literacy and Orality: Studies in the Technology of Communication. Oxford, England: Basil Blackwell, 1988.

Fisher, Larry. Miles Davis and David Liebman: Jazz Connections (Lampeter, United Kingdom: Mellen Press, 1996) 81-82.

Freeman, Philip. Running the Voodoo Down: The Electric Music of Miles Davis. San Francisco: Backbeat Books, 2005.

Gennari, John. Blowin' Hot and Cool: Jazz and It's Critics. Chicago: University of Chicago Press, 2006.

Gioia, Ted. The History of Jazz. New York: Oxford University Press, 1997.

Givan, Benjamin. "Gunther Schuller and the Challenge of Sonny Rollins: Stylistic Context, Intentionality, and Jazz Analysis." Journal of the American Musicological Society 67/1 (2007), 167-237.

Gluck, Bob. You'll Know When You Get There: Herbie Hancock and the Mwandishi Band. Chicago: University of Chicago Press, 2012.

Hohman, Marv. and Charles Mitchell, eds. "Down Beat in Review: A Collection of Lunacy, Prophecy, Controversy and Commentary from 42 Years of the Contemporary Music Magazine.” Down Beat (July 15 1976).

Jost, Ekkehard. Free Jazz. De Capo Press, 1974.

Kahn, Ashley. Kind of Blue: The Making of the Miles Davis Masterpiece. New York: De Capo Press, 2000.

Kania, Andrew. "Works, Performances, Recordings: Classical, Rock, Jazz." In Recorded Music: Philosophical and Critical Reflections, ed. Mine Dogantan-Dack. London: Middlesex University Press, 2010, 3-21.

Kane, Brian. The Sound Unseen: Acousmatic Sound in Theory and Practice. New York: Oxford University Press, 2014.

Katz, Mark. Capturing Sound: How Technology has Changed Music. Berkeley: University of California Press, 2004.

Lawrence, A. H. Duke Ellington and His World: A Biography. New York: Routledge, 2001.

Liebman, Dave. Dark Magus [liner notes]. Europe: Columbia/Legacy, [1997] 1977. 
Litweiler, John. The Freedom Principle: Jazz After 1958. New York: Da Capo, 1984.

MacKenzie, Donald and Judy Wajcman. The Social Shaping of Technology: How the Refrigerator Got Its Hum. (Second edition.) Buckingham, England: Open University Press, 1999.

Losin, Peter. 'Miles Davis Session Details: April 12, 1973.' <

http://www.plosin.com/MilesAhead/Sessions.aspx?s=730412>, 30 March 2015.

—. 'Miles Davis Session Details: September 6 1972', <http://www.plosin.com/ MilesAhead/Sessions.aspx?s=720906>30 March 2015.

Meehan, Norman. 'Creativity in Jazz.' PhD diss., New Zealand School of Music. 2014.

Millard, A. J. America on Record: A History of Recorded Sound. Cambridge, NY: Cambridge University Press, 1995.

Monson, Ingrid. Saying Something: Jazz Improvisation and Interaction. Chicago: University of Chicago Press, 1996.

Moten, Fred. In the Break: The Aesthetics of the Black Radical Tradition.

Minneapolis: University of Minnesota Press, 2003.

Murray, Albert. 'Improvisation and the Creative Process.' In The Jazz Cadence of American Culture, ed. Robert G. O’Meally. New York: Columbia Unversity Press, 1998, 111-113.

Nicholson, Stuart. Jazz Rock: A History. New York: Schirmer Books, 1998.

Peretti, Burton W. The Creation of Jazz: Music, Race and Culture in Urban America. Urbana, IL: University of Illinois Press, 1992.

Philip, Robert. Performing Music in the Age of Recording. New Haven, CT: Yale University Press, 2004.

Pond, Steven. Head Hunters: The Making of Jazz's first Platinum Album. Ann Arbor, MI: University of Michigan Press, 2005.

Porter, Eric. "'It's About That Time": The Response to Miles Davis's Electric Turn.' In Miles Davis and American Culture, ed. Gerald Early. St. Louis, MO: Missouri Historical Society Press, 2001. 
Porter, Lewis. John Coltrane: His Life and Music. Ann Arbor: University of Michigan Press, 1998.

Priestley, Brian. Chasin' the Bird: The Life and Legacy of Charlie Parker. New York: Oxford University Press, 2006.

Prouty, Ken. 'Plagiarizing Your Own Autobiography, and Other Strange Tales: Miles Davis, Jazz Discourse, and the Aesthetic of Silence.' Jazz Research Journal 4/1 (2010).

—. 'Towards Jazz's “Official” History: The Debates and Discourses of Jazz History Textbooks.' Journal of Music History Pedagogy 1/1 (2010), 19-43.

Opstad, Jon. 'The Harmonic and Rhythmic Language of Herbie Hancock's 1970s Fender Rhodes Solos.' Jazz Perspectives 3/1 (2009), 57-79.

Ortner, Sherry. Making Gender: The Politics and Erotics of Culture. Boston, MA: Beacon Press, 1996.

Radano, Ronald. New Musical Configurations: Anthony Braxton's Cultural Critique Chicago: University of Chicago Press, 1993.

Rasula, Jed. 'The Memory of Meaning: The Seductive Menace of Records in Jazz History'. In Jazz Among the Discourses, ed. Krin Gabbard, Durham: Duke University Press, 1995, 134-162.

Sales, Grover. Jazz: America's Classical Music. New York: Da Capo, 1984.

Sanden, Paul. Liveness in Modern Music. New York: Routledge, 2013.

Sanford, David W. "“Prelude (Part 1)" From Agharta: Modernism and Primitivism in the Fusion Works of Miles Davis.' PhD diss., Princeton University. 1998.

Schedel, Margaret. 'Anticipating Interactivity: Henry Cowell and the Rhythmicon.' Organized Sound 7/3 (247-254), 249.

Sewell. William H. 'A Theory of Structure: Duality, Agency, and Transformation.' American Journal of Sociology 98 (1992).

Smith, Jeremy A. 'Sound, Mediation and Meaning in Miles Davis's A Tribute to Jack Johnson'. PhD diss., Duke University. 2008. 
Solis, Gabriel. “"A Unique Chunk of Jazz Reality”: Authorship, Musical Work Concepts, and Thelonious Monk's Live Recordings from the Five Spot, 1958'. Ethnomusicology 48/3 (2004), 315-347.

Szwed, John. So What: the Life of Miles Davis. New York: Simon and Schuster, 2002.

Tackley, Katherine. 'Jazz Recordings as Social Texts.' In Recorded Music:

Performance, Culture and Technology, ed. Amanda Bayley. Cambridge, UK:

Cambridge University Press, 2010.

Tate, Greg. 'The Electric Miles.' Down Beat 50/8 (1983), 22-24, 54.

Taylor, Timothy. Strange Sounds: Music, Technology and Culture. New York: Routledge, 2001.

Tingen, Paul. Miles Beyond: The Electric Explorations of Miles Davis, 1967-1991. New York: Billboard Books, 2001.

Tirro, Frank. Jazz: A History. New York: Norton, 1977.

Tomlinson, Gary. 'Cultural Dialogics and Jazz: A White Historian Signifies.' Black Music Research Journal 11/2 (1991), 229-264.

Waters, Keith. The Studio Recordings of the Miles Davis Quintet, 1965-68. New York: Oxford University Press, 2011.

Wayte, Lawrence. 'Bitches Brood: The Progeny of Miles Davis's Bitches Brew and the Sound of Jazz-Rock.' PhD diss., University of California, Los Angeles. 2007.

Whyton, Tony. 'Acting on Impulse! Recordings and the Reification of Jazz.' In Recorded Music: Philosophical and Critical Reflections, ed. Mine Dogantan-Dack. London: Middlesex University Press, 2008.

Williams, Martin. Jazz in Its Time. New York: Oxford University Press, 1989.

Wood, Naaman. 'Uncle Tom, Massas, and Symbolic Violence: Miles Davis's Rhetoric of Moral Constitution.' Jazz Perspectives 7/1 (2013), 57-75.

Zak, Albin. The Poetics of Rock: Cutting Tracks, Making Records. Berkeley: University of California Press, 2001.

No by-line. 'MR-10 Personal Studio System Info Page', <http://www.dubsounds. com/mr-10.htm>, 30 April 2015. 


\section{Filmography}

No by-line. 'Miles Davis Electric 73 Montreax Part 1.'<https://www.youtube.com $/$ watch? $\mathrm{v}=\mathrm{E} 4 \mathrm{PYJhh} 8000 \&$ index $=1 \&$ list $=\mathrm{PL} 541693 \mathrm{D} 663 \mathrm{C} 56290 \&$ spfreload $=10>30$ March 2015.

No by-line. 'Miles Davis Electric 73 Montreaux Part 2.' <https://www.youtube. com/watch?v=-Fi_DeP55mQ\&list=PL541693D663C56290\&spfreload=10>, 30 March 2015.

No by-line. 'Miles Davis Live at Montreaux1973 Calypso Frelimo - Unreleased Part.' $<$ https://www.youtube.com/watch?v=rfRlZCzqlIg\&spfreload=10> 30 March 2015.

No by-line. 'Univox SR-55 Vintage Analogue Drum Machine Demo.' $<$ https://www. youtube.com/watch?v=HXPAbFr02bk\&spfreload=10>30 March 2015.

\section{Select Discography}

Davis, Miles. A Tribute to Jack Johnson. New York: Columbia. KC 30455, 1971.

—. Bitches Brew. New York: Columbia C2J 45077, 1970.

—. Dark Magus. Europe: Columbia/Legacy, [1997] 1977.

—. In a Silent Way. New York: Columbia CJ 40580, 1969.

—. Filles De Kilimanjaro. New York: Columbia CS 9750, 1968.

—. Get Up With It. New York: Columbia KG 33236, 1974.

—. Miles in the Sky. New York: Columbia, CS 9628, 1968.

- On the Corner. New York: Columbia KC 31906, 1972.

Hancock, Herbie. Head Hunters. New York: Columbia KC 32731, 1973.

Hendrix, Jimi. Band of Gypsys. United Kingdom: Polydor 3194-008, 1970.

Stone, Sly. Fresh. United States: Epic KE 32134, 1973.

_. Riot. United States: Epic KE 30986, 971. 